\title{
Clío y Palas Atenea: Apuntes sobre el papel constitutivo de la Historia en la Teoría de Relaciones Internacionales
}

\author{
Francisco Javier Peñas Esteban*
}

\section{Resumen}

Es posiblemente necesario en estos tiempos que los saberes humanos tengan que dividirse en disciplinas distintas. En algunos casos esta división es muy clara, pero en el campo de las humanidades y de las "ciencias sociales" esta división, por otra parte, necesaria, puede ser - llevándose, como se lleva a un extremo- frustrante y empobrecedora. Ferenc Fehér sostenía que, en última instancia, todas las disciplinas y "ciencias" sociales podían reducirse a la Historia y a la Filosofía. En este artículo se argumenta, por parte de un académico de Teoría de Relaciones Internacionales, la necesidad de la Historia para aquella disciplina. Se enumeran algunos puntos de encuentro y se sostiene que Historia es necesaria para la Teoría de Relaciones Intencionales que el autor propone y que Teoría de Relaciones Internacionales puede ser útil a la Historia. La conclusión es la defensa de la historicidad radical de los hechos, eventos y procesos en las relaciones humanas.

\section{Palabras clave}

Teoría de las Relaciones Internacionales; Historia; Relaciones Internacionales como Historia; Teoría social; Historicidad.

\section{TiTLE}

Clio and Palas Atenea: Some notes on the role of History in the Theory of International Relations

\section{Abstract}

It is possible necessary in our times that human knowledges ought to be divided into distinct disciplines. In some cases, this division is clear, but in the field of humanities and social sciences this division, otherwise necessary, can be -taken to an extreme- frustrating and impoverishing. Frenc Fehér stated that, at the end, all the disciplines and the social sciences have, as ultimate reference, Philosophy and History. In these pages I argue, as an International Relations Theory academic, for the need of history for the former. I enumerate some meeting points and argue why History in indispensable for IRT and what of IRT would be necessary for History. My conclusion is to stand up and defend the idea of the radical historicity of facts, events and processes in human relations.

\section{KEYWORDS}

International Relations Theory; History; International Relations as history; Social theory; Historicity. 
¿Por qué razón saber de dónde vengo me va a decir a dónde voy? Alan Percivale Taylor

\section{ntroducción}

Las disciplinas y teorías sobre la acción humana, individual o grupal, Historia, Ciencia Política, teoría de las Relaciones Internacionales, teoría social, Sociología, etc. se refieren siempre a los mismos sujetos/objetos. En su desarrollo moderno académico, dan lugar a disciplinas separadas por "departamentos" y por la conciencia de sus componentes de que están haciendo algo distinto a los del despacho de al lado. Esta división tiene mucho de sociológicamente artificial y algo de lógica científica. Lo real, por decirlo de alguna manera, es que no se puede, en el siglo XXI, saber todo de todo: es necesario una especialización. Lo sociológicamente perverso es que se establecen barreras entre teorías y disciplinas que obedecen, sobre todo, a cuotas de poder, aunque sea tan mísero como el poder académico.

De tal manera que la historia de relaciones internacionales se estudia, normalmente, en un departamento de historia contemporánea de una facultad de historia o humanidades; y la teoría de Relaciones Internacionales en otro departamento, en España, de derecho internacional público y relaciones internacionales en facultades, de Derecho o Ciencias Políticas y Sociología. De esta manera, se establecen barreras que llevan, por inercia e interés, a una especialización, en gran medida castradora y sin sentido. Pero es así y, aunque seamos conscientes de ello, dedicamos un número de nuestra revista a hablar de la relación entre dos disciplinas, que son tales y distintas por la acción de los académicos, no por su esencia ontológica y epistemología. Eso viene después, como justificación de delimitación de una realidad no delimitable. Luchamos contra las puertas que se han puesto al campo.

Para empezar, nos encontramos con varios problemas algo más que terminológicos.

En primer lugar, el tratamiento que vamos a dar al problema en este trabajo, peca de lo que podríamos llamar desequilibrio. La Historia y las Relaciones internacionales se sitúan ambas en dos planos ontológicos y epistemológicos distintos, aunque el primero sabemos que existe pero llega a nuestras conciencias por la articulación discursiva del segundo. El término historia tiene dos acepciones: (1) El devenir de las relaciones entre los seres humanos, y de estos con la naturaleza de la que forman parte: "El acontecer histórico, el encadenamiento - la marcha de los acontecimientos (en alemán Geschichte) "1; y (2) el estudio, análisis y narrativas sobre ese devenir: "La narración que de tales hechos ofrecen los historiadores (en alemán Historie)"2.

Aunque es difícil, habrá que dejar claro el uso que en determinada frase se hace de la palabra "historia". Podríamos usar historia para el primero, e Historia para el segundo. Aunque, como se verá, la historia es, para nosotros y en la práctica, miles de Historias, o sea miles de relatos escritos y rescritos sobre el pasado. Podríamos distinguir sus acepciones con el uso de " $\mathrm{h}$ " minúscula para la primera y "H" mayúscula para la segunda. No es una distinción original, pero tampoco muy frecuente: la mayoría de los historiadores no la usan.

\footnotetext{
1 ALCOBERRO, Ramon, La filosofía de la historia: ¿un anacronismo?, Filosofía y pensamiento, http://www. alcoberro.info/pdf/FiloHISTO01.pdf [Consultado el 25 de octubre de 2017].

2 Ibídem.
} 
En cualquier caso, manejamos, por así decirlo, dos niveles: el pasado y los relatos que dan cuenta de él.

Sin nos referimos a R/relaciones I/internacionales, la convención, esta vez más difundida, es usar relaciones internacionales, con minúsculas, para las relaciones mismas; y Relaciones Internacionales, con mayúsculas para la teoría que da cuenta de las primeras.

En cualquier caso, manejamos otra vez, para entendernos, tres niveles:

1. "historia" como el pasado o devenir de las acciones y relaciones humanas, y "relaciones internacionales" para las relaciones que, por diversas razones, o según diversas escuelas, se distinguen de otras relaciones. La ambigüedad de este último es patente, pero no es salvable sin entrar a discutir las teorías de las relaciones internacionales (Relaciones Internacionales).

2. "Historia" como relato o relatos sobre el pasado. Pero aquí no hay un término equivalente en relaciones internacionales. Podría ser la Historia de las relaciones internacionales, siempre que aceptáramos radicalmente que el presente siempre es ya historia. Lo que no es el caso en el grueso de la academia.

3. En esta lógica, deberíamos hablar de una teoría de la historia o de la Historia, de la misma forma que hablamos de una teoría de Relaciones Internacionales o, simplemente, Relaciones Internacionales. Lo mismo podríamos decir de una filosofía de la $\mathrm{H}$ /historia y de una filosofía de las $\mathrm{R} /$ relaciones $\mathrm{I} /$ internacionales.

Un problema que aparece es que mientras que en las Relaciones Internacionales la preocupación sobre la teoría es dominante, incluso hasta olvidar o dejar en un papel secundario a la $\mathrm{H} /$ historia, en el campo de los historiadores parece que la teoría de la $\mathrm{H} /$ historia no es moneda corriente. En ambos casos, creo que la idea de una filosofía de la H/ historia o una filosofía de la R/relaciones I/internacionales es algo que, en su más fiel espíritu del positivismo y empirismo, rechazan.

Escribir sobre la relación de la $\mathrm{H} /$ historia con la teoría de Relaciones Internacionales sitúa, objetivamente, la primera en una función subordinada, de apoyo ("baúl de los ejemplos"). Una disciplina auxiliar ${ }^{3}$.

En segundo lugar, no puede hacerse teoría de relaciones internacionales sin recurrir a la historia, pero si se me preguntará el por qué, o se me pidiera una aproximación más explícita, no sabría ni qué ni cómo contestar.

\footnotetext{
3 Soy consciente de que hay un desequilibrio en mi exposición. Mis saberes se sitúan más en la teoría de Relaciones Internacionales, en la que soy un profesional y no en los saberes de la Historia/historiografía, en a que solo soy un ávido lector. Lo que intento es mostrar que la Historia es imprescindible para la teoría social y, más en particular, para las Relaciones Internacionales. Al empezar este trabajo, me di cuenta de la obviedad de que si dentro de la teoría de las Relaciones Internacionales había disputas sobre los diferentes enfoques, también debía haberlos en la historiografía. Lo que pasa es que soy más capaz de hacer una narrativa del desarrollo contradictorio de la teoría das Relaciones Internacionales, que, del desarrollo de los diferentes enfoques, enfrentados o no, en la historiografía; y (2) que no intento comparar ambas disciplinas, sino hacer ver que la teoría das Relaciones Internacionales usa y recurre, salvo casos excepciones y de ahí sus limitaciones, a la Historia y reafirmar la historicidad radical de cualquier fenómeno, proceso, o conflicto, es decir, llamar la atención sobre el imprescindible recuso de/a la Historia.
} 
Para entender las relaciones internacionales ${ }^{4}$, ya sea en su sentido estricto (hoy algo desfasado, pero nuclear) como las relaciones entre estados, como en su sentido laxo, como toda aquella relación que traspase fronteras ( $\mathrm{y}$ tenga efectos públicos), debemos siempre recurrir a la categoría de tiempo/tiempos ${ }^{5}$, del devenir, del discurrir, pues nada es estable, fijo, constante, ni permanente (ni siquiera la geología). Todo es cambiante, móvil, contingente y coyuntural en términos históricos. Ningún evento o proceso aparece tal cual, armado y dispuesto, como Palas Atenea de la cabeza de Zeus.

En este sentido, el equilibrio es efímero, muy efímero, y el desequilibrio lo habitual. Y la historia transcurre, está es la tesis de estas líneas, según la contingencia, la correlación de fuerzas (materiales, ideacionales, emotivas, producidas por agravios, ultrajes, o lo que se vive como injusticias), y la agencia humana. No hay inmovilidad, sino, si acaso, continuidad ${ }^{6}$.

En tercer lugar, para la teoría das Relaciones Internacionales la historia no es un pilar de cemento armado, una base sólida e inamovible. No es el punto arquimédico que añoran todas las discusiones.

En un nivel básico, podríamos decir que una teoría das Relaciones Internacionales que no recurriera a la Historia sería inconcebible, aunque se ha intentado. No puede decirse nada sobre lo internacional que no se refiera a la historia, pues el presente ya es Historia. De la misma manera, la narración de determinado periodo o episodio puede, como veremos, falsear cualquier generalización teórica cuando examinemos las aportaciones de Paul Schroeder.

Pero siendo eso cierto, no topamos con la dificultad planteada en primer lugar. ¿En qué nos apoyamos, en la historia o la Historia? Y, por ende, ¿está tan clara la distinción entre ellas? Finalmente ¿cuántas y variadas interpretaciones hay de un evento, relación o proceso? ¿Cuál de ellas elegir? La conclusión es que, si hay tantos posibles y discutibles puntos arquimédicos, en realidad no tenemos ninguno.

No hay un aspecto determinante o hegemónico en el devenir histórico -lo geográfico, lo económico, lo social, lo político-, sino un flujo recíproco y extraordinariamente complejo entre todos ellos?.

En cuarto lugar, en todo el texto se juega, creo yo, con la ambigüedad de los dos significados de la palabra "historia".

La expresión del pensamiento se complica puesto que ese devenir, ese acontecer es inaprensible e ininterpretable en su totalidad. Solo podemos conocerlo, salvo la pequeña parte que hayamos vivido o compartimos con otros cercanos, a través de lecturas, de forma que siempre se ve obligada a reducir la complejidad a parámetros expresables. Así, hablamos

4 Solemos poner con minúsculas las relaciones mismas y con mayúsculas la teoría o reflexión sobre las mismas.

5 Tiempos, pues de Braudel, sabemos que hay diversos tiempos históricos.

6 BRAUDEL, Fernand, Una lección de Historia, F.C.E, México D.F., 1989, p. 247.

7 AURELL, Jaume et. al. Comprender el pasado. Una historia de la escritura y el pensamiento histórico, Akal, Madrid, 2013, p. 280. 
de la historia y sus efectos solo a través de narrativas estructuradas y donde unos datos figuran y otros no, en función del criterio de pertinencia del historiador o autor cualquiera que sea su disciplina.

$Y$, finalmente, en quinto lugar, una idea excepcionalmente importante, que fue formulada desde dos perspectivas muy distintas por Edward Thompson y Michael Foucault. Este último hace emerger el relato de Boungavilliers, la pérdida de posición de la nobleza de sangre frente a la nobleza de toga, la idea de las mentiras reiteradas de los vencedores que se convierten regímenes de verdad ${ }^{8}$. O el contundente y esclarecedor pensamiento de Thompson: "(la historia) solo recoge lo que ha triunfado (en el sentido de aquellas aspiraciones que anticiparon desarrollos posteriores). Las causas perdidas, los caminos muertos, y los mismos vencidos son olvidados"'.

El objetivo que pretende el artículo es 1 ) mostrar, partiendo del relato de la teoría de las Relaciones Internacionales, los puntos de encuentro con la historia; (2) dejar claro que sin Historia no puede existir ninguna disciplina que trabaje sobre asuntos humanos; y (3) defiendo la radical historicidad de las relaciones humanas, de sus hechos, sus eventos y sus procesos.

Me pongo a ello.

\section{Historiadores e Internacionalistas ${ }^{10}$}

Las relaciones entre Historia y Teoría de la Relaciones Internacionales aparece, a menudo, simple para los internacionalistas: aquellos para los que la historia no juega ningún papel en sus análisis (científicos políticos); aquellos para los que la historia es el baúl de donde se sacan los ejemplos que ilustran las teorías; y aquellos para los que la historia es imprescindible para entender procesos, coyunturas y eventos internacionales ${ }^{11}$.

Entre los internacionalistas, es bastante común el desprecio hacia la historia, porque "[...] la historia de Tucídides nos aclara y enseña tanto como cuando fue escrita en el siglo $V$ a. c. Sospecho que si Tucídides apareciera entre nosotros, después de un breve curso en economía, geografía y tecnología moderna, no tendría apenas problemas para entender la lucha de/por poder actual"12 y, aún más explícitamente, "[...] con honestidad, uno debe preguntarse si los estudiantes de relaciones internacionales saben algo que Tucídides y sus compañeros del siglo $V$ a. c. no supieran sobre el comportamiento de los estados"13.

En el campo de los historiadores de las relaciones internacionales o la política mundial,

\footnotetext{
8 FOUCAULT, Michel, Defender la sociedad. Curso del Collègue de France, 1975-1976, F.C. E., México D.C., 2000 y Nietzsche, la genealogía y la historia, Pre-Textos, Valencia, 1992.

9 THOMPSON, Edward P., "Prefacio" a La formación de la clase obrera en Inglaterra, 1780-1832, Laia, Barcelona, 1977, pp. XIII-XVIII.

10 No me gusta el calificativo para los que nos dedicamos al estudio de las relaciones internacionales. Ciertamente así se denominan a sí mismos algunos estudiosos de Derecho Internacional Público y de las Relaciones Internacionales. En este texto procuraré no usarlo y si lo hago es por pura comodidad.

${ }^{11}$ Importante la reivindicación de la sociología histórica, Hobson, Reus-Smit, etc.

12 GILPIN, Robert, War and Change in World Politics, Cambridge University Press, Cambridge, 1981, p. 211.

${ }^{13}$ Ibídem, p. 227.
} 
encontramos dos ejemplos contrapuestos. El primero sería The Long Peace: Elements of Stability in the Poswar International System de John Lewis Gaddis de $1987^{14}$, en el que uno de los historiadores claves de la Guerra Fría apuesta por escribir un texto siguiendo estrictamente- la teoría de sistemas y, más en concreto, el neorrealismo estructural de $A$ Theory of International Relations de Kenneth Waltz ${ }^{15}$. El resultado es un texto de extremo interés. El capítulo titulado como el libro, "The Long Peace...", escrito durante y desde los parámetros de la Guerra Fría, o -como diría Edward Hallett Carr- con el conflicto bipolar en la cabeza, buscando repuestas a el porqué de la estabilidad en el enfrentamiento, encaja perfectamente en el esquema de Waltz. Del principio organizador del sistema de estados y las capacidades de las unidades, deriva parte de su valor explicativo, que es mucho, precisamente, porque estudia esos dos parámetros de la teoría neorrealista.

En libro posterior de 1992, Gaddis ${ }^{16}$ reniega de la teoría de las Relaciones Internacionales, porque ningún teórico, ninguna teoría fue capaz de predecir la caída de la URSS ${ }^{17}$. A mi parecer, es una desilusión que solo se explica, porque en algún momento (¿1987?) creyó que la teoría de las Relaciones Internacionales tenía, como ciencia, que predecir el futuro de las relaciones internacionales. Ilusión y desilusión muy cientifista y estructuralista, y así le fue. Incluso en uno de sus últimos libros, We Now Know. Rethinking Cold War History 18 , con acceso parcial a los archivos soviéticos de la Guerra Fría, hace un libro de historia, sin ninguna referencia a la teoría.

Un ejemplo contrario es Schroeder, quien en 1996 en su libro The Transformation of European Politics $1763-1848^{19}$, destroza con ejemplos de la política y equilibrio de poder europeos del siglo XIX, las tesis de Waltz que - por definición- se dicen universales desde Tucídides hasta nuestros días ${ }^{20}$.

Dos casos interesantes entre los dedicados a las relaciones internacionales y la historia son Henry Kissinger y Edward Carr. El primero politólogo y estadista (le ahorro al lector mis valoraciones), en su mejor y único libro decente $A$ World Restored ${ }^{21}$, estudia el Congreso de Viena de 1815 centrado en las figuras de Metternich, Castlereagh, Talleyrand y, en menor medida, el zar Alejandro. Llega a conclusiones teóricas sobre el orden internacional legítimo, las potencias "status quo" y las potencias "revolucionarias"22.

${ }^{14}$ GADDIS, John L., The Long Peace. Inquiries into the History of the Cold War, Oxford University Press, Nueva York, 1987.

15 McGraw-Hill, Nueva York, 1979.

${ }^{16}$ GADDIS, John Lewis, The United States and the end of the Cold War, Oxford University Press, Nueva York, 1992.

17 Ibídem, p. 33.

18 GADDIS, John L., We Now Know. Rethinking Cold War History, Clarendon Press, Oxford, 1997.

19 SCHROEDER, Paul W., The Transformation of European Politics 1763-1848, Oxford University Press, Oxford, 1996.

20 SCHROEDER, Paul W., "Why realism doesn't work well for International History? (Whether or not it represents a degenerate IR research strategy)" en VASQUEZ, John A. y ELMAN, Colin (eds.), Realism and balancing of Power: A New Debate, Prentice Hall, New Jersey, 2003, pp. 114-127.

${ }^{21}$ KISSINGER, Henry, A World Restored, Grosset \& Dunlap, Nueva York, 1964.

${ }^{22}$ En el sentido en que Carr habla de la URSS y de Alemania en los años 20, como potencias insatisfechas, o potencias que quieren cambiar el status quo. 
Ignoro si los historiadores hayan acusado o acusen a $A$ World Restored como una instrumentalización de la historia para sacar determinadas conclusiones. En cualquier caso, es un estudio -históricamente- interesante y con conclusiones teóricas de relaciones internacionales sugerentes sobre la construcción y mantenimiento de un orden internacional "legítimo". El deseo de orden se debía a razones diferentes, pero partían de la necesidad de restablecer el orden y el mapa de Europa que Napoleón había puesto patas arriba. También fueron determinantes la personalidad e ideas de los estadistas (Metternich, Castlereagh, Talleyrand y el zar Alejandro); la imposibilidad de convivencia en un mismo sistema de estados de dos principios distintos de legitimidad; la particularidad y unicidad de los eventos históricos y cómo aprender de la historia se hace por analogía, no por identidad ${ }^{23}$.

Por otra parte, destaca Carr (para ser ecuánime no me ahorro las alabanzas), historiador y maestro de historiadores. Su obra ¿Qué es la historia? es el libro de cabecera de muchos y excelentes historiadores ${ }^{24}$. Los estudios de Carr sobre el período 1919-1939 son un buen ejemplo. Primero, en el tiempo, escribió un relato casi empírico sobre la intensa actividad diplomática tras la crisis en el sistema internacional de estados abierta por la Primera Guerra Mundial, o la "Gran Guerra" como se la llamaba entonces. Poco tiempo después, escribió un libro puramente teórico: la contradicción entre las crudas realidades del poder, y la necesidad y trampa de la utopía, que es seminal en lo que respecta la teoría de Relaciones Internacionales ${ }^{25}$. Creo que nadie discute la calidad de Carr como historiador, que antes de ello fue diplomático y estuvo presente junto a John Maynard Keynes en la delegación británica en Paris en 1918. Desafío a quién discrepe de la actualidad, interés y bondad de The Twenty Years' Crisis.

En el primer caso, Kissinger, un politólogo, hace un estudio histórico para sacar conclusiones sobre lo que pudiera ser un "orden legítimo" (nos ahorramos su actividad como hombre de estado); y segundo, Carr, un historiador vocacional, escribe uno de los tres mejores libros jamás escrito sobre Relaciones Internacionales. No parece que las fronteras entre historia y teoría de Relaciones Internacionales sean precisamente muros infranqueables.

\subsection{La "Escuela Inglesa"}

Dos de los grandes representantes de la Escuela Inglesa de Relaciones Internacionales, Martin Wight y Herbert Butterfield, eran historiadores de profesión y escribieron sobre teoría de las Relaciones Internacionales. Wight escribió numerosos artículos, aunque sus tres libros publicados fueron recopilados por sus alumnos ${ }^{26}$. Wight dejó tres grandes aportaciones a la Teoría de Relaciones Internacionales: (1) la idea de que el pensamiento internacionalista puede encuadrarse en tres grandes corrientes, revolucionarismo (Immanuel Kant), realismo (Thomas Hobbes) y moralidad de los estados (Hugo Grocio); (2) la idea de sistema de estados o diversos sistemas de estados que pueden ser contemporáneas, y que su unidad es una

${ }^{23}$ KISSINGER, Henry A., A world Restored..., op. cit., pp. 315-324.

${ }^{24}$ La edición que estoy manejando ahora es la de Ariel, Barcelona, 2010 (traducción de original de 1961).

25 El primero International Relations between de two world wars. 1919-1939 (Macmilllan, Londres, 1990), el original de 1939 y el segundo La crisis de los veinte años (1919-1939). Una Introducción al estudio de las Relaciones Internacionales (Los Libros de la Catarata, Madrid, 2004; traducción de la edición inglesa de 1945).

26 Power Politics (Leicester University Press, Bristol, 1978), International Relations. The Three Traditions (Leicester University Press, Bristol, 1991) y Sistems of States (Leicester University Press, Bristol, 1977). 
cierta cultura común; y (3) la puesta en duda sobre la posibilidad de hacer una teoría política de las Relaciones Internacionales, pues no hay progreso en las relaciones entre estados, sino repetición y recurrencia ${ }^{27}$.

\section{Excurso. Sobre Martin Wight}

Dentro de la teoría de las Relaciones Internacionales hay un ejemplo que combina un enfoque, de alguna forma, civilizatorio, con los presupuestos y parámetros de la teoría de las Relaciones Internacionales más canónica ${ }^{28}$. Me refiero Martin Wight y su Systems of States ${ }^{29}$. El considera que para que exista y perviva un sistema de estados, debe haber una base cultural o "civilizatoria" común. Estudia el Ilamado sistema de los "Estados guerreros" en China, el sistema de la Grecia clásica (premacedónica, desde luego), y el sistema europeo de estados. Estos sistemas no tuvieron contacto entre sí, por situarse lejos en el tiempo y el espacio. Si juntamos los planteamientos de Arnold Toynbee y Donald Wright, el esquema quedaría más o menos así: la humanidad se organiza en civilizaciones que perviven en un mismo momento histórico y con contactos. Dentro de cada civilización, por lo menos en el caso de la civilización europea, los grupos humanos se organizarían en estados distintos y discretos que colaboran y luchan entre sí. Aquí entrarían en juego conceptos clásicos extraídos de la experiencia europea, como equilibrio de poder, Power Politics, etc.

Pero la línea de trabajo de Wight y sus alumnos (Hedley Bull, por ejemplo), epígonos y seguidores, de la llamada Escuela de la Sociedad Internacional o Escuela Inglesa de Relaciones Internacionales, no fue la relación ente las civilizaciones existentes. O bien se movieron en los parámetros del sistema europeo de estados, o en el análisis de cómo ese sistema europeo se hizo internacional/universal con los procesos de descolonización.

Por su parte, Herbert Butterfield, también historiador y con obras publicadas sobre historia de Inglaterra e historia de Europa de XVIII y XIX, publicó su primer libro en 1924. Escribió artículos sobre relaciones internacionales, en concreto sobre el equilibrio de poder europeo, y coeditó con Martin Wight el clásico Diplomatic Investigations ${ }^{30}$. Aquí nos fijaremos

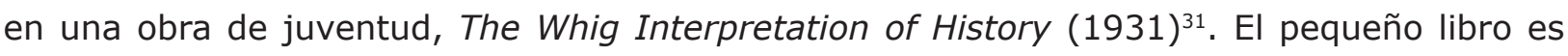
una crítica a la concepción whig, es decir, la concepción de la tradición liberal inglesa, que considera que todo el desarrollo histórico anterior (inglés, por supuesto), es la preparación de lo actualmente existente (1931). En definitiva, es el mejor sistema político posible.

27 WIGHT, Martin, "Why is there no International Theory" en WIGHT, Martin y BUTTERFIELD, Herbert (eds.), Diplomatic Investigations: Essays in the Theory of International Politics, Allen and Unwin, Londres, 1966.

28 Tampoco sería tan extraño pues ambos -Toybee y Wight- fueron historiadores y tuvieran mucho contacto durante sus vidas, por más que Wight fuera algo más joven.

${ }^{29}$ Es un libro póstumo como todos sus libros, que elaboraron sus alumnos, entre otros Hedley Bull, a partir de sus lecciones y de sus apuntes. Publicado por Leicester University Press, Bristol, 1977.

${ }^{30}$ WIGHT, Martin y BUTTERFIELD, Herbert (eds.), Diplomatic Investigations: Essays in the Theory of International Politics, Allen and Unwin, Londres, 1966.

${ }^{31}$ BUTTERFIELD, Herbert, The Whig Interpretation of History, G. Bell and Sons, Londres, 1951 [1 $1^{\text {a }}$ edición en inglés 1931]. 
Argumenta que los historiadores deben resistir la tentación de ver el presente como una ratificación del pasado. Deben escribir contra la narrativa del progreso, hacia adelante o hacia atrás. Deben estudiar el pasado por su valor y en sus propios términos ${ }^{32}$.

El libro critica la tendencia a ver el pasado como una justificación del presente, "[considerando] la historia como una narrativa de los avances y retrocesos del progreso"33. La historia debe estudiarse en sus propios términos, tal y como luego planearon los historiadores como Quentin Skinner, John Pocock, entre otros (Ideas in Context). El objetivo fundamental de la historia sería evaluar las diferencias entre pasado y presente. El reseñador Wright recoge que Butterfield creía en la divina providencia, y en la caída del hombre por el pecado original ${ }^{34}$, lo que entraba en contradicción evidente con su también firme convicción de que los historiadores tenían que, en lo posible, intentar dejar sus valores fuera de su narrativa de la Historia (Butterfield y Keith Sewell lo denominaban technical history). Según le conto a Ved Mehta en una entrevista en 1963, "[...] los historiadores técnicos, digan lo que digan, quieran lo que quieran hacer, no pueden, en realidad, librarse de presuposiciones" ${ }^{\prime 35}$.

La línea entre Historia y teoría de Relaciones Internacionales no existía para Wight y Butterfield. No sé si se les considerará entre los mejores historiadores británicos, pero si fueron los fundadores y maestros de Hedley Bull y otros, y fieles representantes de la Escuela de la Sociedad Internacional.

\subsection{La "Escuela Francesa"}

Siempre se ha asociado a la teoría de las Relaciones Internacionales producida por autores franceses a "las relaciones internacionales como historia", mencionando sobre todo a Pierre Renouvin y Jean Batiste Duroselle. Hoy esta adscripción no se mantiene, porque la lengua dominante en la disciplina es el inglés y si se quiere publicar en The European Journal of International Relations -que se ha erigido como La Revista de los internacionalistas europeos- se debe escribir en inglés.

No obstante, la historia como disciplina es muy fuerte en la academia francesa que ha dado al mundo algunos de sus mejores historiadores como Fernand Braudel o Marc Bloch. Se mantiene la tradición de escribir sobre la historia de las relaciones internacionales, como hicieron Pierre Renouvin y Jean-Batiste Duroselle y más recientemente Charles Zorgbibe ${ }^{36}$.

Esta tradición reaparece, por lo menos en parte, también en el único teórico de las relaciones internacionales que ha logrado romper el monopolio anglosajón del "canon clásico"

\footnotetext{
32 Reseña del libro de Butterfield por WRIGHT, Donald, "SEWELL, Keith C., Herbert Butterfield and the Interpretation of History (Studies in Modern History). New York: Palgrave Macmillan. 2005. Pp. xii, 280" en The American Historical Review, vol. 111, n², 2006.

${ }^{33}$ Ibídem.

${ }^{34}$ Para entender lo siguiente es necesario saber que tanto Wight como Butterfield eran cristianos de convicciones profundas. No es obvio en la obra de Wight, pero si en este libro de Butterfield y en las declaraciones que ahora recogemos.

35 WRIGHT, Donald, "SEWELL, Keith C..., op. cit.

${ }^{36}$ En España se publicó su Historia de las relaciones internacionales, vol. I, De la Europa de Bismarck hasta el final de la Segunda Guerra Mundial y vol. II Del sistema de Yalta a nuestros días, Alianza Editorial, Madrid, 1997.
} 
de la disciplina: Raymond Aron ${ }^{37}$. Aron, que era polifacético, pero bien se le puede denominar sociólogo, dedica una de las cuatro partes de su Paz y guerra entre las naciones (1962), a la historia ${ }^{38}$, lo que es muy inusual en un manual o una obra que pretende ofrecer una teoría global.

Pero Aron fue la excepción. La gran aportación de autores franceses a las Relaciones Internacionales se hizo en el campo de su historia, de la mano de Pierre Renouvin, JeanBatiste Duroselle y su escuela. Como historiadores estuvieron implicados e influidos por los debates historiográficos que tuvieron lugar, a lo largo de décadas, desde la fundación por Marc Bloch y Lucien Febvre en 1929 de Annales d'histoire économique et sociale ${ }^{39}$. Renouvin y Duroselle ${ }^{40}$ vivieron estos debates, revindicando siempre que la "Historia de las Relaciones Internacionales" asumieron la herencia de Bloch, Febvre, Braudel, etc. y siempre mantuvieron esta perspectiva historiográfica: "[En este libro] el estudio de las relaciones internacionales se ha enfocado, en la perspectiva de las investigaciones históricas, desde muy diversos puntos de vista"41.

Renouvin considera que hay tres enfoques fundamentales - "tenemos pues tres claras tendencias diferenciadas que se manifiestan en el estudio"42 - en el estudio de la historia de las relaciones internacionales: la historia diplomática (1), aquella que considera que el hilo central son las relaciones entre los gobiernos preocupados por su seguridad, potencia o prestigio y, por tanto, "su predilección (es) el papel desempeñado por los hombres"43 que toman decisiones y negocian diplomáticamente o, en su caso, declaran la guerra. Esta escuela sabe que existen "fuerzas profundas", pero si se negara el papel de los que negocian y toman decisiones caeríamos en "una especie de determinismo histórico"44. "El error de este historiador es creer que los documentos diplomáticos son suficientes para el estudio de la historia de las relaciones internacionales"45. La perspectiva adoptada por la historia estructural (2) se centra en las "fuerzas subyacentes" y en los "movimientos profundos": - "agitación de superficie', nada importan los incidentes o/y accidentes, ni los y gestos de los hombres de estado, dice Braudel"46 - , para comprender las relaciones entre estados se deben conocer los "movimientos profundos" económicos y sociales. En tercer lugar, (3) Renouvin se pregunta ¿qué quiere decir que el estudio de la sicología colectiva aporta al historiador una base sólida? El estudio de las influencias de las ideas "es el problema más difícil de la investigación histórica"47 y no se puede suponer que las ideas de teóricos o escritores de una época reflejen la mentalidad de la mayoría de la población.

\footnotetext{
37 ARON, Raymond, Paz y guerra entre las naciones, Alianza Editorial, Madrid, 1985.

38 Siendo las otras tres: "Teoría", Praxeología" y "Sociología".

39 Después llamado Annales. Economies, sociétés, civilisations, y nuevamente renombrado en 1994 como Annales. Histoire, Sciences sociales. Quien me ilustro sobre esto es mi colega Pedro Martínez-Lillo.

${ }^{40}$ RENOUVIN, Pierre y DUROSELLE, Jean-Batiste, Introducción a la política internacional, Rialp, Madrid, 1968.

${ }^{41}$ RENOUVIN, Pierre, (dir.), "Introducción general", Historia de las relaciones internacionales, vol. I, Aguilar, Madrid, 1960, p. IX. Mis gracias a mi colega Eduardo Carreño que me proporcionó este texto.

${ }^{42}$ Ibídem, p. XI. Resaltado mío.

${ }^{43}$ Ibíd.

${ }^{44}$ Ibíd.

${ }^{45}$ Ibíd., p. XII.

${ }^{46}$ Ibíd., p. X.

${ }^{47}$ Ibíd., p. XIII.
} 
Por último en esta noticia de los planteamientos de Renouvin y su escuela, tres apuntes más: en primer lugar, lo estudiado va desde las fuerzas más impersonales y procesos de larga duración, hasta el papel ejercido por los "hombres de gobierno"; en segundo lugar, se pretende hacer una historia narrativa, no un esquema analítico, es decir, narrar los acontecimientos más relevantes; y por último un tercero, Renouvin y sus colegas sitúan su trabajo dentro del gremio y del campo de la Historia, de la historiografía y ninguna mención se hace a la Ciencia Política o a la teoría de las Relaciones Internacionales. En el caso de esta escuela francesa, la teoría de las Relaciones Internacionales se nutre de la historia y del trabajo de los historiadores que además y tienen conciencia y voluntad de serlo. Pero ¿qué teoría de las Relaciones Internacionales se puede hacer ignorando lo que ellos narran?

\subsection{Civilizaciones}

Si hay una obra que puede considerarse "macrohistoria", desde un punto de vista occidental y contemporáneo, seria Estudio de la Historia de Arnold Toynbee, publicada entre 1933 y $1961^{48}$. Lo relevante para la teoría de Relaciones Internacionales sería que la unidad de análisis la encuentra Toynbee en las "civilizaciones". El autor señal la existencia de veintiséis; cinco que no llegaron a desarrollarse plenamente; dieciséis que han desaparecido; y cinco que todavía podemos identificar.

Toynbee planteó que la unidad inteligible del estudio histórico no es ni el estadonación, ni la humanidad como un todo, sino "[...] cierta comunidad humana que hemos llamado sociedad"49. Toynbee identifica cinco sociedades vivas, y frente a la objeción de que lo único que tienen en común estas es haber sido calificadas de campos inteligibles de estudio por el investigador, el autor da un paso más y sostiene que lo que tiene en común es que, normalmente, son conocidas como civilizaciones para distinguirlas de las sociedades primitivas. Abarcan una población numerosa, tienen costumbres y formas de pensar semejantes y suelen estar asociadas a grandes religiones. El autor sostiene que, no obstante los mapas políticos y económicos hayan sido "occidentalizados", "[...] los lineamientos de las cuatro civilizaciones vivas no occidentales" siguen estando claros ${ }^{50}$.

Charles Tilly sostiene que "[...] dentro de unos límites, podemos recoger evidencias a favor y en contra de la pretensión de Toynbee de que las grandes civilizaciones, definidas por la participación interdependiente de las personas en un sistema concreto de premisas culturales, constituyen las unidades inteligibles más amplias el análisis histórico [...]"51.

Otro ejemplo de una historia mundial basada en las civilizaciones, como grandes unidades de espacio y tiempo desde el año 500 a. c., hasta los años posteriores a la Segunda

\footnotetext{
${ }^{48}$ Aquí usaremos la versión abreviada en tres tomos autorizada y bendecida por Arnold J. TOYNBEE que realizo D. C. SOMERVELL y para la que TOYNBEE escribió un Prefacio. Este compendio A Study of History. Abridgement, fue publicado originalmente por Oxford University Press en 1946. Utilizo la traducción castellana realizada por Luis Grasset y publicada en 3 tomos, Alianza Editorial, Madrid, 1970.

${ }^{49}$ Estas líneas están inspiradas en PEÑAS, Francisco Javier, Occidentalización, fin de la Guerra Fría y relaciones internacionales, Alianza Editorial, Madrid, 1997, en el que dedico un capítulo a Toynbee. Para ello utilicé el llamado compendio antes mencionado. La cita es de la p. 34.

${ }^{50}$ Ibídem, Compendio, p. 69.

51 TILLY, Charles, Grandes estructuras, procesos amplios, comparaciones enormes, Alianza Editorial, Madrid, 1991, p. 83.
} 
Guerra Mundial, es la obra $A$ world History de William H. McNeill52. A pesar de todas las virtudes del libro, de su indudable erudición y la multicausalidad de los cambios de y entre civilizaciones (aspectos de la producción, sobre todo agrícola, de la cultura, de las formas de hacer la guerra, etc.), la obra apenas apunta un apartado teórico, que - posiblemente- el autor no considera necesaria explicitar. En este sentido, la obra afecta poco a lo escrito en este epígrafe:

"La idea organizadora es simple: en una edad determinada, el equilibrio mundial entre culturas se ponía en peligro por la aparición de uno o más centros donde los hombres consiguieron crear un civilización inusualmente atractiva o poderosa. Sus vecinos y los vecinos de sus vecinos se vieron tentados u obligados a cambiar sus formas tradicionales de vida, algunas por la copia o el préstamo de técnicas e ideas, pero más a menudo ajustando y cambiando cosas para subsistir con más tranquilidad en la escena local"53.

En su breve conclusión, McNeill apunta "[...] que cualquiera que reflexione sobre el tumultuoso y enredado record de la vida humana en la tierra puede sentirse desconcertado por la cantidad de brutalidad y estupidez que los hombres se han mostrado entre ellos [...] "Y concluye que todas las grandes civilizaciones "[...] han aceptado un sistema ético que enfatizaba la bondad y el amor"54.

Si la unidad de análisis de la organización de la humanidad son las civilizaciones, en puridad lo que debería estudiar una teoría de las Relaciones Internacionales, que ya no podría llamarse así, serían las relaciones entre ellas, el papel que unas y otras juegan en el surgimiento, esplendor o decadencia de otras. Parece acertado, y no excesivamente pretencioso, decir que hoy por hoy las "civilizaciones" han sufrido un proceso transformador (desigual, desde luego) de influencia mutua, y no podemos considerarlas como todos homogéneos, por más que compartan ciertos rasgos en las costumbres, creencias religiosas, etc.

En el ámbito académico de la ciencia política, solo conozco, al respecto, la afamada tesis de Samuel Huntington ${ }^{55}$ sobre el choque civilizatorio como el nuevo omnipresente conflicto internacional. Los acontecimientos recientes pueden obligarnos a reconocer que su denostada lectura del mundo de la posguerra fría, contenía más elementos de lucidez de lo que admitíamos, por más que critiquemos su visión de las civilizaciones escasamente porosas, muy unificadas, etc. Hay, hoy en día, aspectos civilizatorios en conflicto en el mundo.

\footnotetext{
52 MCNEILL, William. H., A World History, Oxford University Press, Oxford, 1978. El libro fue escrito según el autor entre 1964 y 1965, rescrito en 1970 y actualizado para esta edición de 1978. El libro intentaba escribir la historia mundial más brevemente que el anterior -The Riseof the West: A History of the Human Community (University of Chicago Press, Chicago, 1963)- e intentando "hacer que mi visión personal de toda la historia de la humanidad más accesible a los estudiantes y a los lectores en general y, "por más que imperfecta mantuviera las virtudes de la cohesión e inteligibilidad... (un texto) que pudiera ser asumido, recordado y diera lugar a la reflexión" (p. VI).

${ }^{5}$ Ibídem, p. VI.

${ }^{54}$ Ibíd., p. 540.

${ }^{55}$ Apareció en primer lugar en forma de artículo, "The Clash of Civilizations", Foreign Affairs, 1993.
} 


\section{Excurso. Sobre The Clash of Civilizations de S. M. Huntington \\ La intuición era certera y la argumentación de conveniencia}

Hay un fenómeno que se repite hace décadas. De vez en cuando, un texto (usualmente publicado en Foreign Affairs), una conferencia o libro, se ponen de moda en el establishment político de Washington y, por lo tanto, en todo el mundo. Pasó con una conferencia en 1990 reproducida en los medios de Lawrence S. Eagleburger, Unchartered Waters. Eagleburger fue segundo del Departamento de Estado de EEUU. con James Baker, y luego Secretario de Estado cuando Baker pasó a organizar la fracasada campaña presidencial para el segundo mandato de George Bush.

Su tesis era que, con el fin de la Guerra Fría, los que antes era conocido y previsible (chartered waters), ahora era impredecible y no había cartas de navegación para este, posiblemente, convulso período. Pasó con el libro de Paul Kennedy titulado The Rise and Fall of the Great Powers: Economic Change and Military Conflict from 1500 to 2000 de 1987, y su tesis del overstreaching del poder de las grandes potencias, en este caso, léase EEUU. Pasó con Francis Fukuyama y su artículo de 1989 The End of History ${ }^{56}$, que acabó publicado en libro $1992^{57}$.

En ese sentido, Huntington se inscribe en estas de modas sobre lo internacional en el establishment washingtoniano. Cuando Huntington escribió su artículo, el yihadismo estaba en bloque Giles Kepel llama $1^{a}$ oleada y no era considerado más que una molestia ${ }^{58}$. Se barajaban otros enemigos para sustituir a la fenecida URSS (por ejemplo, el narcotráfico).

El texto de Huntington ${ }^{59}$ es infumable y las civilizaciones que describe responden, según muchos autores, a los diversos grupos étnicos presentes en EEUU. Pero hay dos afirmaciones que hoy aparecen como certeras: (1) la política internacional será un choque de civilizaciones; y (2) hay una civilización islámica que no admite los parámetros occidentales sobre la vida pública e, incluso, la existencia de una vida pública y una privada.

En nuestro siglo y desde 2001, los estados occidentales han declarado una guerra contra el "terror", es decir, contra el "terrorismo", es decir, contra la yihad. Y esta guerra no se libra en términos de un discurso político, sino ético (bien/mal) o civilizatorio (civilización/barbarie). Y eso por ambos bandos.

Lo cierto es que no hay lugar para situar esta guerra en el terreno de lo político, si es que alguien quisiera hacerlo, puesto que los salafistas, yihadistas y demás, niegan $-y$ ese es un rasgo de su civilización- la existencia de esferas

${ }^{56}$ FUKUYAMA, Francis, The End of History and the Last Man, Free Press, Nueva York, 1992.

57 Ibídem.

58 KEPEL, Gilles, El terror entre nosotros. Una historia de la yihad en Francia, Península, Barcelona, 2016.

${ }^{59}$ En forma de libro, The Clash of Civilizations and the Remaking of World Order, Simon and Schuster Inc., Nueva York, 1996. 
separadas lo político, lo económico, lo público, lo religioso, lo privado, etc.

Esto en lo que se refiere al punto 2. Con respecto al punto 1 , poco que decir, salvo que la "lucha (civilizatoria) contra el terror" ocupa gran parte de las políticas exteriores de los estados, pero no, ni mucho menos, el campo de las relaciones internacionales. Y lo vemos en Siria donde hay una lucha civilizatoriareligiosa, pero hay luchas por la hegemonía en la región entre estados -Irán y Arabia Saudita- y grandes potencias: EEUU y Rusia.

Lo que "logró" Huntington es incluir en el vocabulario político, de política exterior y de relaciones internacionales, la idea de la existencia de civilizaciones y de sus posibles encontronazos. Ideas que habían dejado de estar vigentes, formuladas en estos términos, desde el auge del colonialismo europea a finales del XIX y principios del XX.

\subsection{Macrorelatos}

Una de las obras de macrohisotoria que ha influido directamente sobre la teoría de las Relaciones Internacionales, es el libro de Immanuel Wallerstein, The Modern World System, en dos volúmenes ${ }^{60}$. Quizá sea este el lugar adecuado para hacer referencia a la teoría marxista, al marxismo. Wallerstein y sus seguidores de la Escuela Fernad Bruadel de la SUNY se declaran herederos de Karl Marx. Braudel escribió muy acertadamente que "[...] Marx fue una figura monumental en la historia intelectual y política moderna. Nos ha dejado un gran legado [...] sin embargo, deberíamos tomarnos más en serio que él no era marxista[...]Marx era un hombre del siglo XIX cuya vida y obra estaba inevitablemente limitada por esa realidad social... Utilicemos pues sus escritos del único modo sensato: como los de un compañero de lucha que sabía tanto como él sabía"61.

La teoría del sistema-mundo tiene su origen en las discusiones teóricas sobre las causas del subdesarrollo que tuvieron lugar en el mundo académico en los años setenta. La teoría de la modernización, hegemónica entonces en el mundo anglosajón, consideraba la economía mundial como un agregado de unidades, en alguna medida concertadas, y cuyas trayectorias se suponía que eran o serían similares o equiparables. Está teoría, que consideraba las economías estatales como unidades de análisis, fue puesta en cuestión, entre otros, por André Gunder Frank y su "desarrollo de subdesarrollo"62. Gunder Frank sostenía que la explicación del subdesarrollo no debía buscarse en las causas internas de las sociedades subdesarrolladas, sino en las relaciones de estas con los países desarrollados: "La explotación del mundo subdesarrollado estaba en la base y era la condición de la prosperidad del mundo desarrollado; el mundo desarrollado solo lo era creando subdesarrollo en el otro"63.

${ }^{60}$ WALLERSTEIN, Immanuel, El moderno sistema mundial vol. 1. La agricultura capitalista y los orígenes de la economía-mundo europea en el siglo XVI, Siglo XXI, Madrid, 1979 y El moderno sistema mundial, vol. II. El mercantilismo y la consolidación de la economía mundo europea, 1600-1750, Siglo XXI, Madrid, 1984.

61 WALLERSTEIN, Inmauel, El capitalismo histórico, Siglo XXI, Madrid, 1998, p. VIII.

62 GUNDER FRANK, Andrè, The sociology of development and the underdevelopment of sociology, Pluto Press, Londres, 1971.

63 DALE, Roger, "Nation state and international system The World System perspective" en McLENNAN, Gregor, HELD, David y HALL, Stuart, The Idea of the Modern State, Open University Press, Milton Keynes, 1984, p. 184. 
La teoría de la dependencia consideraba que los países subdesarrollados podían desarrollarse por vías diferentes a las impuestas por el centro. Por ejemplo, La desconexión ${ }^{64}$, como sostenía Samir Amin era posible y necesaria. La peculiaridad del sistema-mundo está, en parte, expresada en su propio nombre: considera al mundo un sistema en el que el estado de cada una de las partes afecta y es afectado por los demás y, por tanto, la alternativa tiene que ser sistémica. Es una perspectiva mundial, pues es el mundo la unidad de análisis, no este o aquél grupo. Habla del sistema-mundo capitalista porque es el capitalismo, entendido en términos de comercio y no de producción, el que proporciona la lógica del sistema y da coherencia. Para Wallerstein "los estados naciones no son sociedades que tienen historias separadas y paralelas, sino parte de un todo"65.

La economía-mundo fue fruto de la derrota de los Habsburgo cuando intentaron crear un imperio mundo. La expansión geográfica de la economía-mundo europea, supuso la eliminación de otros sistemas-mundo y la absorción de los residuales mini sistemas.

Para él el método óptimo para la teoría social consiste en "[...] llevar a cabo el análisis en paradigmas sistemáticos, suficientemente amplios espacial y temporalmente para contener una 'lógica' rectora que 'determine' el sector más amplio de realidad secuencia, a la vez que reconozca y tenga en cuenta que estos paradigmas sistémicos tienen un principio y un fin, y que, por tanto, no han de concebirse como fenómenos 'eternos'"'66.

Para nuestro autor la mayor parte de las unidades descritas habitualmente como sistemas sociales - etnias, comunidades, naciones-estado, etc.- no son sistemas totales. Por el contrario, argumenta que los únicos sistemas sociales reales son, por una parte, las economías de subsistencia; y, por otra, el sistema-mundo.

A efectos de relaciones internacionales, lo más llamativo es la clasificación de los estados en aquellos de centro y los ubicados en las áreas periféricas: "No digo estados periféricos, pues la característica de las áreas periféricas es que el estado indígena es débil, oscilando entre la no existencia (es decir, una situación colonial) y una situación con escaso grado de autonomía (es decir, una situación neocolonial)"67. Los análisis de Wallerstein sobre el estado empiezan en su situación en la economía-mundo: centro, periferia o semiperiferia; y tal situación determina, en el sentido fuerte del término, su política exterior.

En los años noventa se sostenía que la teoría de las Relaciones Internacionales estaba dividida en tres corrientes: el realismo, la teoría liberal de la interdependenciay la teoría de la dependencia. Esta última ya no se sustentaba en las teorías de los años setenta, sino crecientemente en el sistema-mundo. Así, de todos los autores mencionados más arriba, solo Wallerstein y su Frenad Braudel Center dependiente de la SUNY, ha creado escuela en relaciones internacionales.

${ }^{64}$ AMIN, Samir, La desconexión, IEPALA, Madrid, 1988.

${ }^{65}$ Está descripción de los rasgos del sistema-mundo está sacada de PEÑAS, Francisco Javier, Occidentalización..., op. cit., pp. 71-78.

${ }^{66}$ WALLERSTEIN, Immanuel, "Análisis de los sistemas mundiales" en GIDDENS, Anthony y TURNER, Jonathan (eds.), La teoría social hoy, Alianza Editorial, Madrid, 1990, p. 405.

67 WALLERSTEIN, Immanuel, El moderno sistema mundial vol. 1.La agricultura capitalista y los orígenes de la economía-mundo europea en el siglo XVI, Siglo XXI, Madrid, 1979, p. 492. 
Esta escuela, diversa y plural, está unida por una cierta referencia al marxismo, a la economía política y los países en "vías de desarrollo" (itoma eufemismo oficial!), y está ligada o aparece como heredera de la teoría de la dependencia del CEPAL. Comparte algunos rasgos, como que los estados se comporten en función de su situación en el centro, periferia o semiperiferia del capitalismo; los procesos de longue durée braudelianos, entre otros ${ }^{68}$. En los manuales (imalditos manuales!) aparece bajo el rótulo de "teoría de la dependencia".

Merece la pena incluir en estos macrorelatos la aportación de Eric Wolf titulada Europe and the People without History. Tuvo y tiene influencia no solo por su calidad y erudición, sino porque por primera vez - hasta donde yo conozco- escribió una historia del mundo no etnocéntrica. Por el contrario, enfatizó la globalización mundial desde el año 1400.

La referencia a Friedrich Hegel es explicita y dice mucho sobre el propósito del autor. Desde 1492, o 1400, que es la fecha que él señala como el comienzo de su estudio, el mundo no puede entenderse desde una Europa cristiana, civilizada, etc. que se expande por el mundo frente a unas poblaciones pasivas. Nuestro mundo no puede entenderse sin "los pueblos occidentales y no occidentales en un proceso de escala mundial"69.

Impelidos por estas fuerzas a realizar actividades convergentes, gentes de distintas geografías, orígenes y socializaciones, fueron empujados en la tarea de construcción de un common world. En este proceso, las diversas sociedades y culturas -europeas, asiáticas, americanas y africanas - sufrieron grandes transformaciones. "El proceso global iniciado con la expansión europea es también (la de los africanos, americanos, etc.) su historia. No hay, por tanto, ancestros contemporáneos, no hay gente sin historia"70.

El libro de Eric Wolfe se propone también otra tarea: "elaborar una historia analítica" para contrarrestar la ascendencia en las ciencias humanas de una racionalidad formal ${ }^{11}$ que ya no indaga en las causas de las acciones humanas, sino que - fundamentalmente- busca soluciones técnicas a problemas concebidos en términos técnicos. Su ataque se dirige a aquellos que parecen haber olvidado que la población humana construye sus culturas en la interpretación con otros, y no en el aislamiento.

La obra de Jane Burbank y Freferick Cooper, Empires in World History. Power and the Politics of Difference ${ }^{72}$, nace de unos cursos donde se planteaban ensanchar las perspectivas de la "historia política del mundo", sin recurrir a los relatos manidos de las transiciones de los imperios a estados naciones, la distinción entre estados modernos y premodernos, y el enfoque en Europa y Occidente ${ }^{73}$. La resiliencia de las formas imperiales de dominación ponía

\footnotetext{
${ }^{68} \mathrm{La}$ asunción de los largos procesos lleva a títulos aparentemente chocantes como El largo siglo XX

de Giovani ARIGHI (Akal, Madrid, 1999) que empieza examinando la economía veneciana del siglo XIV. Lo chocante no excluye la calidad y sugerencia del texto en cuestión.

${ }^{69}$ WOLF, Eric, Europe and the Peoples without History", California University Press, Berklye, 1982, p. IX.

${ }^{70}$ Ibídem, p. 385.

${ }^{71}$ Ibíd., p. IX.

72 BURBANK, Jane y COOPER, Frederick, Empires in World History. Power and the Politics of Difference Princeton University Press, Princeton, 2010.

${ }^{73}$ Ibídem, p. XI.
} 
en cuestión al estado-nación como natural, necesario e inevitable, e instaba a "explorar la amplia gama de formas en las que la gente a lo largo del tiempo, y para bien o para mal, han reflexionado sobre la política y organizado sus estados"74. El trabajo examina una variedad de Imperios (Roma, China, el imperio mongol, Rusia y EEUU), como "imperios en sus continentes", el colonialismo, "la guerra y la revolución en un mundo de imperios, 1914 a 1945".

Uno de sus conceptos recurrentes es political imagination, que se refiere a cómo la gente imagina su situación, relaciones y posición en un contexto político dado (en el caso de estos autores, imperial); y el tipo de relaciones sociales e instituciones que eran concebibles y/o plausibles en una situación dada ${ }^{75}$. El último capítulo reagrupa las tesis desplegadas en este largo relato histórico sobre los imperios. Es difícil no llegar a la conclusión de que para los autores los imperios, no los estados, han sido los protagonistas de la historia mundial hasta nuestros días. Y la consiguiente pregunta: "Ciertamente, siendo conscientes de las desigualdades en poder y recursos que desembocaron en los imperios, y los han mantenido hasta nosotros. La ruptura de los imperios ha tenido, tiene y tendrá efectos perturbadores"76.

Ninguno de los poderes imperiales que subsisten se ha vinculado a un proyecto religioso, a la religión secular de la modernización, o al comunismo. Las religiones monoteístas, que antiguos gobernantes pensaban que traerían coherencia y legitimidad a la construcción del imperio, trajeron cismas y disenso en vez de unidad. Los imperios menos exigentes en temas religiosos son los que han tenido una vida más larga. Aunque los imperios se han enfrentado a las diferencias culturales de los pueblos que incorporaban a su dominio con enfoques diferentes, algún tipo de tolerancia de la diversidad ha sido esencial para su longevidad77.

Para Burbank y Cooper, los imperios de una forma u otra convivieron con la diferencia; los estados-naciones consideran que las diferencias pueden ser superadas por el reclamo de la idea de nación, o la participación en las instituciones del estado; o, al contrario, por la exclusión, la expulsión o la asimilación obligatoria.

Los autores concluyen: "Vivimos con las consecuencias de estas trayectorias desiguales y rotas para huir de los imperios, con la ficción de una soberanía equivalente, y la realidad de la desigualdad dentro y entre estados [...] Hemos examinado una amplia variedad de formas con las que los imperios incorporaban y hacían distinciones entre su población, las consecuencias de mantener a los pueblos separados por desiguales o intentar hacerlos y eliminar la desigualdad y hacerlos parejos y similares. El desafío para el futuro es imaginar nuevas polities que reconozcan los fuertes deseos de pertenencia política, igualdad y respeto mutuo"78.

En lo que respecta a la teoría de las Relaciones Internacionales, una lectura de la

\footnotetext{
${ }^{74}$ Ibíd., p. 3.

75 Ibíd., p. 16.

${ }^{76}$ Ibíd., p. 453.

77 Ibíd., p. 457.

${ }^{78}$ Ibíd., p. 459
} 
historia milenaria como aquella de formas de organización y distribución imperiales, pone en cuestión la narrativa clásica que se hacía sobre Tucídides, o sobre la Paz de Westfalia. Por otra parte, la diversidad de formas de pertenencia, coerción, dominio político y distribución de los bienes, nos obliga a repensar la centralidad del estado-nación en la teoría de las Relaciones Internacionales.

Michael Mann emprendió una obra cuyo propósito era encontrar las fuentes del poder social mediante el estudio comparado de los sistemas políticos desde Mesopotamia hasta nuestros días. Se ha publicado la obra en cuatro dos volúmenes: el primero, desde Mesopotamia hasta el siglo XVIII; el segundo, desde 1760 hasta 1914; el tercero 1890-1945; y el cuarto, de 1945-2011.

Mann, conocido por ser un destacado miembro de la llamada "sociología histórica", ofrece una macrohistoria cuya fuente de inspiración no parece ser, por lo menos en un primer momento, la historiografía, sino la teoría social siguiendo las enseñanzas de Max Weber. Mann no considera que pueda hacerse teoría social sin historia y, a su vez, considera que "a strong sense of Theory"79 permite determinar los factores centrales e iniciar una dialéctica entre datos e hipótesis.

Vamos aquí a dar cuenta de la obra de Mann en la medida en que su macrohistoria se relacione con la teoría de las Relaciones Internacionales. No obstante, conviene apuntar algunos presupuestos. Primero, las sociedades están constituidas por múltiples redes de poder solapadas y que se interceptan en el tiempo y espacio; ni son unitarias, ni son cerradas, ni son una "totalidad". Segundo, para Mann existen solo cuatro grandes formas de redes de poder: "la mejor manera de trabar un relato general de las sociedades, su estructura, su historia, puede hacerse en términos de interrelación de lo que yo llamo las cuatro fuentes el poder social: ideológica; económica, militar y política". Y tercero, estas son redes superpuestas de interacción social, como también organizaciones, medios institucionales para conseguir objetivos humanos ${ }^{80}$.

Distingue varias expresiones de ese poder, aunque tales distinciones son, inevitablemente, algo artificiales: colectivo o distributivo; extensivo o intensivo; y autoritario o difuso. Estas diferentes formas en las manifestaciones de las redes de poder, dan lugar a sistema sociales diferentes: imperios, naciones-estado, clanes, etc. ${ }^{81}$. Estamos hablando de unas intrincadas redes de conexiones, intereses y visiones, que se superponen, enfrentan y combinan de forma particular en cada caso.

¿Es buena historia? No me siento preparado para decirlo. Es un modelo que funciona y explica, que desafía todas las simplificaciones. Cada caso es único. ¿Es posible, entonces, una generalización? Si es así, la generalización es el modelo mismo que funciona en los casos estudiados y, por tanto, abre vías de investigación.

\footnotetext{
79 MANN, Michael, The Sources of Social Power. vol. I, A History of Power from the beginning to A.D. 1760, Cambridge University Press, Cambridge, 1986, p. VII.

${ }^{80}$ Ibídem, pp. $1-2$.

${ }^{81}$ Ibíd., pp 7-27.
} 
Pondremos un buen ejemplo del análisis de un acontecimiento: la Gran Guerra. El capítulo XXI del segundo tomo de la obra de Michael Mann, Empirical culmination over the top: Geopolitics, class struggle and World War ${ }^{82}$, es la mejor y más compleja explicación multicausal de por qué se produjo la Primera Guerra Mundial. Mann propone lo que yo he llamado el paradigma del embrollo, es decir, una multitud de actores: estados; estadistas; financieros; clases sociales; estados mayores de ejércitos sin nada que hacer; partidos; socialdemócratas; redes de conexión; eventos como el atentado de Sarajevo (sobre el que volveré más adelante y que es historia eventual siguiendo a Braudel); tendencias a medio plazo y de larga duración como la formación de los estados naciones, o la problemática herencia de la retirada del Imperio Otomano de los Balcanes.

Este texto incluye una crítica a la explicación realista y neorrealista de la Gran Guerra, y examina ambas explicaciones clásicas dominantes del imperialismo: la económica (Hobson, Lenin, etc.) y la social (Schumpeter y, en gran medida V. I. Lenin en su texto La bancarrota de la II Internacional de 1915). Sus conclusiones desafían toda clasificación, por no decir, todo paradigma: "(agosto 1914) [...] fue el resultado de consecuencias inintencionadas e imprevistas de la interacción del solapamiento de redes de poder entrecruzadas. Los actores buscaron y deambularon sin rumbo entre estrategias cuyas consecuencias eran imprevisibles y eventualmente devastadoras [...] La Gran Guerra ejemplifica, con horror, las estructuras de los estados y de las sociedades modernas"83.

Ningún enfoque, en el manido estilo de paradigma vislumbrará ni de cerca la tragedia. La mayoría de los textos de historia o teoría de las Relaciones Internacionales que han tenido cierta influencia, no pretenden ser macrohistoria. Un caso paradigmático sería el ya mencionado The Twenty Years' Crisis de Carr.

Otro ejemplo ilustrador lo ofrecen Robinson y Gallagher en Africa and the Victorians. The Official Mind of Imperialism ${ }^{84}$. Lograron ahí introducir una nueva explicación del fenómeno del imperialismo europeo. Hobson, Lenin, Bujarin, etc. eran portavoces de una explicación económica; Schumpeter de una sociológica; y Robinson y Gallagher de una visión que, en algunos casos, se llamó "periférica"85. Estos explicaban el imperialismo inglés, su protectorado sobre Egipto y la guerra de los Boers, tanto por rebeliones nativas, como por razones políticas y un cierto absent-mindedness.

\subsection{La sociología histórica}

Por lo que sé, la llamada Sociología Histórica (Tilly, Skocpol, Bendix, Anderson, entre otros) ha tenido cierta influencia entre los historiadores. El libro de Perry Anderson Lineages of Absolutist State ${ }^{86}$ tuvo, y quizás siga teniendo, mucho predicamento entre historiadores de

82 Véase capítulo 21 en MANN, Michael, The Sources of Social Power. vol. II, Cambridge University Press, Cambridge, 1993.

${ }^{83}$ Ibídem, pp. 796-798. No he leído todavía los volúmenes III y IV que se publicaron en 2012.

${ }^{84}$ ROBINSON, Ronald y GALLAGHER, John, Africa and the Victorians. The Official Mind of Imperialism, Macmillan, Londres, 1981 [2a edición en ingles].

85 Ver FIELDHOUSE, David K., "Imperialism: an historical review", The Economic History Review, vol. 14, n 2, $1966,187-209$

${ }^{86}$ Verso, Londres, 1985. Hay traducción castellana en Editorial Siglo XXI. 
la Edad Moderna. El proceso de formación del Estado unitario que culmina para la teoría de las Relaciones Internacionales en la Paz de Wesfalia de 1648, y que empieza gestarse con los príncipes de los siglos XVI y XVII, es más complejo que lo dado por hecho. En este sentido, otros textos de sociología histórica como las obras de Charles Tilly: War Making and State Making as Organized Crime ${ }^{87}$ y The Formation of the State en Western Europe ${ }^{88}$. En este último, Tilly escribe un capítulo seminal, Reflections on the History of European state-making.

Mann escribió un texto hace décadas que situaba el estado, relativamente, autónomo de las clases y grupos económicos. Quería romper con el determinismo marxista sobre el estado como órgano de la burguesía sin más, lo que - por cierto- se contradice con el análisis de Marx en El 18 de Brumario de Luis Bonaparte, y el estatalismo propio de los internacionalistas y cinéticos políticos, que no tienen en cuenta el papel de la clase dominante en la constitución y comportamiento de los estados: The autonomous power of the state ${ }^{89}$.

Generalmente, la llamada sociología histórica que trabaja con fuentes indirectas, en la mayoría de los casos (Tilly sería una excepción), aporta elementos muy interesantes para historiadores y estudiosos de las relaciones internacionales. En las últimas décadas, estudios de teoría de las Relaciones Internacionales han revindicado la necesidad de recurrir a esta disciplina para los análisis de relaciones internacionales ${ }^{90}$.

Obviamente la Historia tampoco es algo trasparente y nítido, no hay verdad evidente en los hechos históricos. Están sujetos a la interpretación y reinterpretación, pues -como diría Carr- el presente no tiene más que una existencia conceptual, como línea divisoria entre el pasado y el futuro"91. Nuestra lectura del pasado se hace siempre con los parámetros del presente, con sus inquietudes y sus interrogantes ${ }^{92}$. En la obra The dying animal93, Philip Roth dice que cada vez que se lee una novela, explícitamente, Guerra y Paz, cada lector -o el mismo diferentes coyunturas de su vida - lee una novela distinta. La distinción no está en el texto, sino en el lector. Roth, si fuera un académico y no un novelista, podría haber estado hablando de la historiografía. En lo que respecta a nosotros, cada lector que parte de las relaciones internacionales, lee cosas distintas en los textos históricos o sobre historia.

\subsection{Sociología histórica, teoría de las Relaciones Internacionales y el constructivismo historicista}

En este epígrafe me referiré a un carril de dos direcciones: (1) de la sociología histórica a la teoría de las Relaciones Internacionales y (2) de la teoría de las Relaciones Internacionales,

\footnotetext{
${ }^{87}$ En EVANS, Peter, RUESDESCHEMEYER, Dietrich y SKOCPOL, Theda (eds. ), Bringing the State back in, Cambridge University Press, Cambridge, 1985.

88 TILLY, Charles (ed.), The formation of national states in Western Europe, Princeton, Princeton University Press, 1975.

${ }^{89}$ En HALL, John A. (ed.), States in History, Basil Blackwell, Oxford, 1986.

90 Por ejemplo, HOBSON, John. M., Historical Sociology and International Relations, Cambridge, University Pres, Cambridge, 2002 y REUS-SMIT, Christian "Reading History through constructivist eyes", Millenium. Journal of International Studies, vol. 37, n 395, 2008, pp. 395-414.

${ }^{91}$ DUJOVNE, León, La filosofía de la historia. De Nietzsche a Toynbee, Galatea/Nueva Visión, Buenos Aires, 1957, p. 35.

${ }^{92}$ CARR, Edward Hallett, ¿Qué es la historia?, Ariel, Barcelona, 2010 [1 ${ }^{\text {a }}$ edición en inglés de 1961], p. 172.

${ }^{93}$ ROTH, Philip, The dying animal, Houghton Mifflin Harcourt, Nueva York, 2001.
} 
en este caso del constructivismo, a la sociología histórica y a la historia entendida como el estudio y narración del pasado.

En la primera dirección circulan autores como John $\mathrm{H}$. Hobson (The State and International Relations ${ }^{94}$ ), Stephen Hobden (International Relations and Historical) y la y la obra colectiva editada por Hobson Historical Sociology and International Relations ${ }^{95}$. Su definición de historicismo, "en contra de como lo define Popper, es una forma de investigación histórica que reconoce la especifidad de los acontecimientos dentro de su contexto temporal y espacial y rechaza las categorías trans-históricas que hacen de la historia un relato isomórfico"96.

A principios del siglo XXI se publicaron una serie de libros, (2) nuestra dirección contraria, de los que aquí mencionaremos cuatro, que partiendo de un constructivismo menos cerca de la teoría canónica, representada por Robert Keohane, como el constructivismo de Alexander Wendt ${ }^{97}$ y más reflectivista e ideacional basaban sus análisis en la historia, generalmente en forma de la historia comparada. Empezando por Christian Reus-Smit, The Moral Purpose of the State. Culture, Social Identity and Instutional Rationality in International Relations ${ }^{98}$ que, después de unos capítulos teóricos como "The Constitutional Structure of International Society", analiza el concepto de soberanía y "propósito del estado" mediante en el espíritu de Tilly de Grandes estructuras, procesos amplios, comparaciones enormes ${ }^{99}$ la comparación de la organización de la comunidad política en la Grecia clásica, el estado renacentista, el estado absolutista y el moderno, para destacar la importancia de ideas y normas. En este mismo espíritu, con el mismo método y la misma editorial (no es casualidad, como veremos), Mlada Bukovansky estudia el concepto y práctica de la legitimidad en su Legitimacy and Power Politics ${ }^{100}$, con capítulos teóricos y comparaciones de la legitimidad en el Antiguo Régimen, la Revolución Americana y la Revolución francesa. Daniel Philpott examina el concepto y práctica de la soberanía en Revolutions in Sovereignty ${ }^{101}$, con el mismo esquema -capítulos teóricos y comparaciones históricas- pero contrastando La fundación del sistema de estados soberanos de Westfalia y La revolución de las independencias coloniales y estas como La expansión global del sistema de estados y, por último Heather Rae y su State identities and the homogenisation of peoples ${ }^{102}$ sobre la construcción del estado moderno como "limpieza étnica" de judíos y moriscos de la corona de Castilla y Aragón, de hugonotes bajo el reinado de Luis XIV, de armenios en el Imperio Otomano (1915-1916) y en la desmembración de la antigua Yugoslavia a finales del siglo XX.

\footnotetext{
94 HOBSON, John A., The State and International Relations, Cambridge University Press, Cambridge, 2000.

95 HOBSON, John A., Cambridge University Press, Cambridge, 2002.

96 RAE: isomorfo: Dicho de dos o más cuerpos: Que, con diferente composición química, presentan igual estructura cristalina y pueden cristalizar asociados; p. ej., el espato de Islandia y la giobertita, que forman la dolomía. HOBSON, John M. y LAWSON, George, "What is History in International Relations?", Millennium. Journal of international studies, vol. 37, $\mathrm{n}^{\circ} 2,2008$, p. 422.

97 WENDT, Alexander, Social Theory of International Politics, Cambridge University Press, Cambridge, 1999.

98 REUS-SMIT, Christian, Princeton University Press, Princeton, 1999.

99 TILLY, Charles, Grandes estructuras, procesos amplios, comparaciones enormes, Alianza Editorial, Madrid, 1991.

100 BUKOVANSKY, Mlada, Legitimacy and Power Politics, Princeton University Press, Princeton, 2002.

101 Y otra vez, PHILPOTT, Daniel, Revolutions in Sovereignty, Princeton University Press, Princeton, 2001.

102 En este caso no es Princeton U. P., sino Cambridge University Press, Cambridge, 2002.
} 
El método es el clásico de historia comparada de la Sociología Histórica pero instrumentalizado por internacionalistas para esclarecer conceptos fundamentales de la teoría de las Relaciones Internacionales. El uso de la historia que estos teóricos de las Relaciones Internacionales hacen no es el del "baúl de los ejemplos" sino una "filosofía constructivista de la historia"103. Me tomaré la licencia de citarlo in extenso:

"Argumento que una filosofía constructivista de la historia está constituida por cuatro asunciones teóricas interrelacionadas: en la medida en que las estructuras sociales dan forma a la acción individual y colectiva, las estructuras ideacionales son más importantes que las estructuras materiales; las identidades de los actores informan sus intereses; las estructuras y los agentes se constituyen mutuamente, y, a través de la comunicación (lingüística y simbólica) las estructuras ideacionales condicionan a los actores y a la acción, y, a la vez, los actores reproducen las estructuras[...] la filosofía constructivista de la historia es esencialmente 'skinneriana'[...] los hechos de la historia son dependientes de su interpretación, se convierten en 'hechos' y adquieren algún significado[...] " gracias al trabajo de los historiadores"104.

Para estos autores, los conceptos básicos de la teoría de las Relaciones Internacionales, pasando a través del tamiz de la historia, se des-reifican y se des-naturalizan, se perfilan y logran coherencia.

\subsection{Una crítica al maltrato de la historia por parte de los internacionalistas}

Paul Schroeder presentó en un simposio organizado por International Security ${ }^{105}$ en 1996, un texto donde resumía las posibles colaboraciones entre la historia y la teoría de las Relaciones Internacionales, el uso y el abuso, el acoplamiento (fit), y la no adaptación (misfit) entre los teóricos y analistas de las relaciones internacionales y los historiadores. Señala tres diferencias: (1) mientras que los científicos políticos buscan regularidades y grandes pautas, el historiador está obsesionado con la riqueza de los detalles y escrupulosa fidelidad a los hechos descubiertos en el proceso de investigación; (2) existen diferencias entre las disciplinas nomotéticas y las disciplinas ideográficas, es decir, entre aquellas que buscan establecer leyes y predicciones, y aquellas que aspiran a relatar situaciones particulares; y (3) "la historia busca 'explicar' acontecimientos y procesos no asignándolas causas específicas, sino intentando entrar dentro de ellos, y lograr una interpretación empática. En alemán, Verstehen, es decir, lo que hoy llamaríamos en la teoría social, comprensión ${ }^{106}$ :

"En lo que respecta a la empatía y Verstehen, pueden ser útiles, e incluso importantes para llegar al tipo de juicios que busca el historiador. La posibilidad de lograr cierta comprensión empática de la conducta humana es una presuposición de la posibilidad del conocimiento histórico [...] La historia presupone la posibilidad del entendimiento de la acción y las experiencias humanas desde dentro [...]vías que son imposibles con otros objetos de

\footnotetext{
103 REUS-SMIT, Christian, "Reading History...", op. cit., p. 399.

$104 \quad$ Ibídem, pp. 399-400 y 404.

105 SCHOROEDER, Paul, "History and International Relations Theory: Not Use or Abuse, but Fit or Misfit", International Security, vol. 22, n 1, 1997.

106 Ibídem, p. 65.
} 
estudio"107.

Schroeder considera que, en principio, la forma de investigar de unos y otros es distinta, lo que no implica que no sea posible enriquecimiento mutuo. Pero señala tres áreas de diferencias:

1. El fenómeno por explicar, la forma en que este fenómeno es concebido a efectos de explicación, el arte y el método de investigación. Para la historia, el fenómeno a explicar es el cambio en la vida humana, en la sociedad y en las instituciones y así a lo largo del tiempo.

2. Los historiadores conciben y explican el cambio humano, principalmente, en términos de conducta humana, es decir, los actos propositivos de los agentes. Aun reconociendo que la vida humana está limitada y moldeada por factores no humanos, los historiadores insistirían en que la historia del cambio diacrónico es historia, no biología. La Peste Negra se explica por factores biológicos; la historia de la Peste Negra es la historia de las respuestas humanas y los cambios que se produjeron.

3. Finalmente, la forma en la que los historiadores intentan explicar el cambio histórico y el tipo de explicación que buscan, es donde la diferencia se hace más aparente. La ciencia política parte de la formulación de una hipótesis, examina las aportaciones científicas relevantes, expone y defiende una estrategia de investigación, y pone a prueba la hipótesis, llegando a conclusiones que niegan, reafirman, afinan o modifican la hipótesis inicial. El historiador procede mediante la identificación de un problema, un fenómeno histórico ignorado, no explicado o bien del que se ha dado cuenta de forma errónea. Procede luego a constituir un "[...] pequeño universo de investigación mediante la definición del desarrollo histórico que pretende estudiar". Intentan abarcar toda la evidencia posible y accesible, para llegar a un juicio sinóptico, es decir, una amplia interpretación de ese desarrollo, basada en su examen desde ángulos diferentes para lograr entender su nacimiento, significado y qué compresión de él es la que mejor integra la evidencia accesible ${ }^{108}$.

En resumen, la tarea y contribución del historiador es llegar al mejor juicio sinóptico sobre las causas y significado del cambio histórico ${ }^{109}$.

Schroeder identifica dos áreas de claro misfit ${ }^{110}$. Primero, cuando los científicos políticos no tienen en cuenta, suficientemente, que los hechos históricos que extraen, organizan y estilizan a su gusto en los relatos, son selecciones y construcciones de los historiadores que (1) sirven para explicar el cambio histórico; (2) son entendidos como parte de la conducta humana, como agencia y no como comportamiento; y (3) forman la base para los juicios sinópticos sobre causas, significados e importancias ${ }^{111}$.

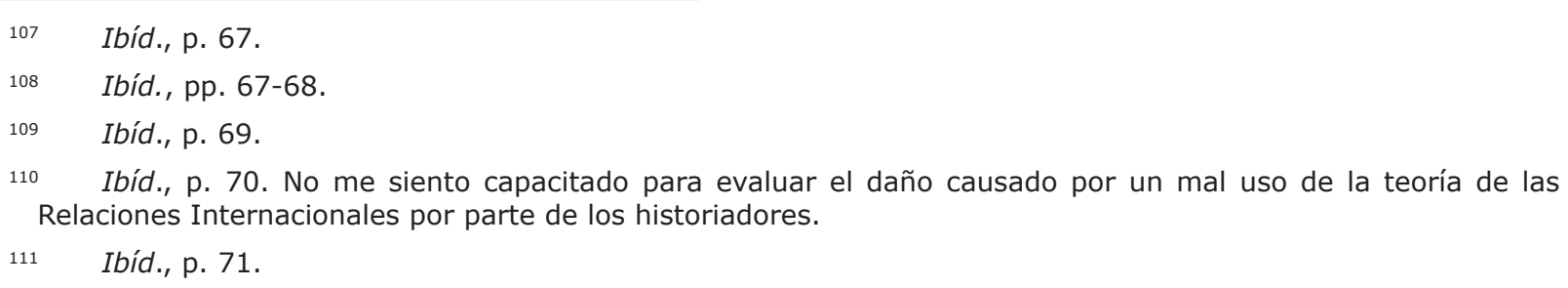


En segundo lugar, existe un área. Un amplio espectro de enfoques de política internacional que se extiende desde el neorrealismo duro; la teoría de juegos; hasta análisis matemático-estadístico de transacciones y correlaciones de fenómenos codificados, según los parámetros de la econometría a los que no puede aplicarse la anterior discusión. En estos casos, no se trata de misfit entre la historia y la teoría de las Relaciones Internacionales, sino de total falta de conexión: el propósito de estudio, las correlacionas entre fenómenos fijos, el concepto de lo que se quiere descubrir o explicar y los resultados, "[...] son tan remotos y ajenos a la profesión del historiador, que ninguna conversación o colaboración es posible"112.

\section{Necesitamos de la Historia porque somos historia, todo es historia}

Creo que sería hacer "trampa" argumentar de forma contundente que no puede hacerse "ciencia" social sin recurrir a la Historia -en nuestro caso, no podría proponer una teoría de las Relaciones Internacionales obviando la Historia- la narrativa del pasado, dando a entender que la Historia no está sujeta a los mismos dilemas, contradicciones, diversidad de escuelas o, en términos "clásicos", aunque algo casposos, pugnas paradigmáticas, que cualquier otra incursión o narrativa sobre las relaciones humanas y sociales.

Clío es una inspiración, una musa, no un "punto arquimédico", inamovible y seguro refugio, contenedor de verdades y referente último de respuestas. Como buena hija de Zeus, es "humana, demasiado humana", y hace trampas, engaña, seduce, ilumina e inspira, pero no es Jehová.

\subsection{Epistemología y ontología de la Historia}

Mi postura epistemológica es reflectivista, por llamarla de alguna manera, y escéptica (en los parámetros del uso vulgar del término). Hay una realidad, pero la acción humana funciona con la lectura, el mapa, que se ha hecho de eso que llamamos realidad y que nos incluye ${ }^{113}$.

En el tema en el que nos movemos, hago mía la pregunta "¿cómo es posible una historia de la Verdad, cuando nos damos cuenta de que la Verdad tiene historia?" En el ámbito del conocimiento histórico, ¿cómo podemos saber/conocer sin ninguna garantía de verdad? En el terreno de la política, ¿cómo podemos gobernar y usar el poder sin garantías de emancipación y universalismo político? En el ámbito de la ética, ¿cómo podemos vivir sin la seguridad de "códigos y mandamientos universales"114, es decir sin Dios?

La ontología y la epistemología son conceptos, unas señales en nuestros mapas mentales, una palabra, un relato, un texto. Es importante recordar esta obviedad, pues el concepto depende de la lente que restringe o amplia el campo. Las características que otorgamos a los objetos, como también aquellas que en determinado momento destacamos, son unas u otras dependiendo del contexto de la argumentación, o bien del discurso. Podemos hablar de la ontología de la fruta, así como de las ontologías diferentes de las peras y las

\footnotetext{
$112 \quad$ Ibíd., p. 73.

113 Me duele contradecir a Descartes y siempre me he movido por el cogito ergo sum, pero no es aceptable separar Realidad y mente.

114 DEAN, Mitchell, Critical and effective histories, Routledge, Londres, 1994, p. 215.
} 
manzanas. Ambas son válidas dependiendo del contexto. Asimismo, podemos hablar de las formas de acercarnos a esos objetos: mirándolas, dándoles un mordisco, o situándola encima de la cabeza del hijo de Guillermo Tell, etc.

Detrás de toda esta enumeración se esconde el tema de la(s) filosofía(s) de la historia. Detrás de la obra de cualquier historiador o internacionalista hay siempre una visión de mundo. Y por más que la idea de "filosofía(s) de la historia" tenga un olor rancio y decimonónico, lo que intenta recoger está ahí, explícita o implícitamente.

Se dice que fue Voltaire en 1765, bajo el seudónimo de Abate Bazin, el primero en utilizar el término. Nunca fue un término aceptado sin reparos o universalmente. El gran y muy influyente historiador Jacob Burckhardt (1818-1897), se opuso de manera decidida a la filosofía de la historia porque veía en ella la versión más sofisticada y perversa del partidismo. Por eso anota: "Ante todo, nada de filosofía de la historia". La expresión filosofía de la historia es para Burckhardt una "contradictio in adiecto", un "centauro", ya que la historia coordina y, por tanto, no es filosofía; mientras que la filosofía subordina y, por tanto, no es historia.

Burckhardt rechaza la filosofía de la historia porque es un sistema que tiene en su base un error. Ese error es creer que hay una época privilegiada que alcanza la perfección, y que todas las épocas precedentes son simples grados de desarrollo hacia esa época perfecta. Una vez que se descubre ese error, todo el sistema se viene abajo. Frente a los "peligros de la filosofía de la historia"115, y pese a las pegas de Burckhardt, se sigue haciendo filosofía de la historia, a veces bajo el epígrafe teoría de la historia, pues nunca cesa la búsqueda de sentido.

Hace mucho tiempo leí en un texto de Anthony Smith, posiblemente National Identity ${ }^{116}$, algo que - al cabo de décadas - todavía recuerdo. Según mi memoria, Smith sostenía que, puesto que todo autor tiene una "filosofía de la historia" que está implícita en su obra, él se disponía a poner por escrito la suya. La verdad es que no recuerdo más, pero me quedo con la afirmación de que tras cada obra de ciencias sociales, hay una filosofía de la historia.

Diferentes filosofías de la historia y concepciones historiográficas sobre los sujetos y las redes de procesos, acontecimientos e instituciones; la existencia o inexistencia de leyes de la historia; las metáforas geométricas del círculo, la espiral, el bucle, la línea ascendente y la línea quebrada en múltiples posiciones; "el eterno retorno" metafísico de Friedrich Nietzsche; la idea de progreso; la metáfora del "valle de lágrimas" que nos lleva hacia Dios, tan abundante en el góspel; los tipos de "civilizaciones" de Toynbee; o la forma imperial hegemónica de organizar las redes de coerción y distribución que diría de Burbank y Cooper, tienen que afectar a los (cansinamente) llamados paradigmas en la teoría de las Relaciones Internacionales.

Carr sostenía que "[...]el actual filosofo de la historia, que esforzadamente mantiene un difícil equilibrio entre los riesgos del determinismo objetivo y el pozo sin fondo de la

\footnotetext{
115 NAVARRO PÉREZ, José, "Jacob Burckhardt, el escepticismo histórico y el pesimismo político", Respublica, n 6, 2000, pp. 116-117.

116 SMITH, Anthony D., National Identity, Penguin Books, Londres, 1991.
} 
relatividad subjetiva, consciente de que pensamiento y acción se hayan inextricablemente entrelazados y que la naturaleza de la causalidad, tanto en la historia como en la ciencia, parece tanto más escurridiza cuanto mayor es la firmeza con la que se pretende asirla, está más ocupado planteando interrogantes que respondiéndolos"117.

Carr tenía en cuenta los planeamientos epistemológicos y ontológicos de las ciencias naturales y las ciencias sociales de finales del siglo XIX y principios del XX. En este sentido, rebate "[...] la profunda convicción de que los hechos son neutrales", y que el progreso consiste en descubrirlos y aprender de ellos. Tal visión correspondía, según Carr, a una "[...] concepción racional-liberal del mundo $[\ldots]^{\prime \prime}$ que hoy no puede darse por supuesta ${ }^{118}$.

\section{2. ¿Qué Historia?}

Sería de recibo exponer - dentro de los límites de mi ignorancia (la de un ávido lector de Historia, no un historiador) - que quiero decir cuando afirmo la necesidad imprescindible de la Historia; o más modestamente, qué tipo de Historia -creo- que serviría más y mejor al tipo de teoría de las Relaciones Internacionales que sostengo.

Pero, ante todo, debemos ser conscientes que narrar un acontecimiento, en "ciencias" sociales, es siempre esquematizar y simplificar una realidad más compleja e inabarcable. La elección de lo narrado es arbitraria, no en el sentido de no tener argumentos para la elección, sino en términos de dar énfasis a las elecciones del narrador. La realidad nunca podrá ser contenida en un relato, e intentarlo lleva a la parálisis y la infertilidad. La elección por el autor es necesaria, no puede hacerse de otra manera.

En este sentido, apunto (1) que debería ser una lectura y narrativa del pasado autoconsciente, de su carácter de construcción social de un tiempo y un lugar. Una historia donde el narrador, el historiador, tenga siempre en mente que (2) escribimos sobre el pasado desde el presente ${ }^{119}$; (3) que los historiadores eligen - según su criterio- el trigo (relevante) de la paja (irrelevante), para el nudo de lo que quieren contar; (4) que el historiador establece el marco espacio-temporal del problema, evento o contingencia que investiga, y este marco es arbitrario y solo se justifica por la plausibilidad que otorga (o no) a la narración; (5) que es consciente de que el vocabulario elegido no es neutro, sino que el significante afecta al significado; (6) que el lector lee diferentes narrativas de un mismo texto, en función de las preguntas que buscan respuestas, y cada lector lee su propia narrativa según, también, su situación espacio-temporal; y que (7), queramos o no, todos escribimos para el príncipe, aunque hay infinitos príncipes a los que servir.

Keith Jenkins nos advierte que la "fragilidad epistemológica" de la Historia permite

\footnotetext{
117 CARR, Edward Hallett en The Times Literary Supplement (1953), citado por EVANS, Richard J. "Introducción" a ¿Que es la historia?, Ediciones Planeta, Barcelona, 2010, p. 15.

118 Ibídem, p.14.

119 "Considerando que no existen interpretaciones del pasado que no estén basadas en algún tipo de presuposición al respecto (en términos de George Steiner, ficciones axiomáticas) y teniendo en cuenta que las interpretaciones del pretérito se construyen en el presente, parece remota la posibilidad de que los historiadores puedan deshacerse de su presente para aprehender el pasado ajeno en sus propios términos", JENKINS, Keith, Repensar la Historia, Siglo XXI, Madrid, 2009, p. 53.
} 
que las lecturas de los historiadores sean "extremadamente diversas"120. Argumenta cuatro razones, que, en mi entender, serían tan extensibles como la fragilidad epistemológica a todas las "ciencias" sociales y, desde luego, a una hipotética "ciencia" de las relaciones internacionales.

En primer lugar, apunta a la inconmensurabilidad del pasado, a cómo ningún relato pueda coincidir de forma exacta con él. Segundo, argumenta que ningún relato puede recobrar el pasado tal y como fue, porque "[...] el pasado no fue un relato sino que se compone de acontecimientos, situaciones, etc. [...] por lo que los relatos solo pueden contraponerse a otros relatos. Tercero, Jenkins no difiere de lo ya dicho repetidamente: la Historia sigue siendo, inevitablemente, una construcción personal, "[...] una manifestación de la perspectiva del historiador como narrador". Y cuarto, sostiene que -en cierto sentido- sabemos más sobre el pasado que quienes vivieron en él.

Al traducir el pasado a términos modernos y utilizar unos conocimientos que quizás - antes fueran inasequibles, el historiador descubre aquello que ha quedado olvidado del pasado, y es capaz de reunir piezas que hasta entonces nadie había encajado. "Es más, debido a que las historias enfatizan las conexiones y restan importancia a las continuidades y las rupturas [...] las historias tal como las recibimos (tal vez) sean más inteligibles de lo que el pasado jamás llegó a ser"121.

También postula una tesis cierta, pero controvertible en su formulación: "[...]la epistemología nos enseña que nunca podremos conocer realmente el pasado y que el abismo entre el pasado y la Historia (historiografía) es ontológico, está en la misma naturaleza de las cosas, de manera que todo esfuerzo epistemológico para salvar ese abismo es inútil". Esta posición, aplicable a la hipotética "ciencia" de las relaciones internacionales, apunta a una certidumbre: la realidad es inabarcable, pero desbarra - a mi entender- en el calificativo "inútil". Hay lecturas más plausibles que otras, por ejemplo, las que son conscientes de los límites que marca Jenkins. Es verdad que el esfuerzo epistemológico nunca puenteara el "abismo", y no encontraremos la Verdad, pero en el camino nos desharemos de múltiples lecturas míticas y más engañosas.

Permítaseme ahora enumerar algunos rasgos de esa Historia que busco, que creo necesaria. La historia, al ser cambio y continuidad, debe ser - primero- consciente de lo que Koselleck llama Los estratos del tiempo ${ }^{122}$, o bien las diferentes duraciones que nos indica Braudel: desde aquello que se mueve más lentamente como la geografía física, al chispazo momentáneo que enciende un conflicto. Hay niveles en el devenir, influenciándose, e incluso- determinándose, unos a otros, lo cual debe ser recogido en la narración histórica.

Segundo, una Historia no teleológica. Una historia que no cree en la divina providencia, ni el juicio final, ni el alfa y omega de Pierre Teilhard de Chardin ${ }^{123}$, ni en leyes que -

\footnotetext{
$120 \quad$ Ibídem, pp. 14-18.

$121 \quad$ Ibíd., p. 18.

122 KOSELLECK, Reinhart, Los estratos del tiempo: estudios sobre la historia, Paidós, Barcelona, 2001.

123 P. TEILHARD DE CHARDIN (1881-1955) fue un jesuita, paleontólogo y filósofo francés que aportó una muy
} 
inevitablemente- nos lleven a ese comunismo tan parecido al paraíso religioso. Una historia que avanza, incluso, a pesar de algunos retrocesos. Tampoco puede ser una historia que nos remita al eterno retorno nietzscheano, por más que uno pueda decir y dice "esa película ya la he visto".

Parto de una negación rotunda de una teleología de la historia. No contemplo la existencia de un ser o idea supremo al margen de la historia y lo humano. No creo que haya lugar a discusión, es una cuestión de fe, que fructifica en paradigmas diferentes e inconmensurables. Abusando de lo que David Hume calificaba de "falacia naturalista": las cosas, los acontecimientos y los procesos no tienen intrínsecamente sentido, es decir, por sí mismos. El sentido, el significado, los adjetivos calificativos los ponemos los hablantes.

Tercero, asumo que la historia no tiene un sentido, un significado último, ni obviamente- una culminación. Hay autores y gente que sí da sentido/significado al devenir y cambio humano, a la historia. No lo comparto, pero lo entiendo: el sentido/significado de la historia es de vital importancia. Arendt decía que la vida no era la búsqueda de la Verdad, sino del Sentido.

Esta importancia se expresa en tres razones:

1. El sentido/significado de la historia y, por tanto, de nuestra situación en ese devenir, afecta nuestra identidad y acción; no quizás la inmediata utilitaria, pero sí en términos generales.

2. Volviendo Hume, sin ese sentido/significado de la historia no podríamos adjudicar nombres ni, sobre todo, adjetivos, a las cosas, sucesos o procesos. Útil e inútil, bueno o malo, son meras palabras si no están inscritas en un marco más amplio; y ese marco no podría existir sin un sentido/significado más o menos claro de la historia, en cuanto devenir del pasado al fugaz presente y futuro.

3. El sentido de la vida, de la historia, como el universo ético al que uno responde, es el de cada cual. Es verdad o no, pero es propio y se intenta vivir a su altura.

\section{Excurso. Carr y la idea de progreso}

Carr se pregunta si hay progreso en la historia y comentando las Lectures on Modern History (1906) de Acton (cuya visión es que la historia es un progreso sin fin hacia la libertad), sostiene que "[...] si el historiador ha de salvar su hipótesis de progreso, creo que debe estar dispuesto a tratarlo como un proceso en el que las exigencias y condiciones de los períodos sucesivos impondrán su contenido específico"124. Para el historidor, el final del progreso todavía no ha desembocado. Es algo infinitamente remoto... el contenido de la historia no puede ser captado más que a medida que vamos experimentándola.

personal y original visión de la evolución. Su concepción de la evolución, considerada ortogenista y finalista, equidistante en la pugna entre la ortodoxia religiosa y científica, propició que fuese atacado por la una e ignorado por la otra. Suyos son los conceptos Noosfera (que toma prestado de Vernadsky) y Alfa y un Omega punto de partida y de llegada de la evolución. Este Omega cristiano, aunque fue condenado por la iglesia (por la negación de la parusía o Segunda Venida de Cristo, tal como la entiende la Iglesia).

124 CARR, Edward. Hallett, ¿Qué es la historia?, op. cit., pp. 180-181. 
"[...] La noción de una meta finita y claramente definible del progreso en la historia, tantas veces postulada por los pensadores del siglo XIX, ha resultado inaplicable y yerma. La creencia en el progreso no significa la creencia en un proceso cualquiera que sea este, automático e ineluctable, sino en el desarrollo progresivo de las potencialidades humanas"125.

Carr no espera la perfectibilidad del hombre o el paraíso terrenal venidero... pero "[...]me basta con la posibilidad de un progreso ilimitado - un progreso que no esté sometido a ningún límite que debamos tener en cuenta-, progreso cuyas metas solo pueden irse definiendo conforme avanzamos hacia ellas y cuya validez nada más puede comprobarse en el proceso de alcanzarlas"126.

Su vena escéptica apunta que nadie tiene la obligación de creer en el futuro de la historia, ni en el futuro de la sociedad. El significado de la historia no está fuera de la historia misma.

Cuarto, ninguna historia es universal y definitiva, pues no hay solo un discurso sobre la historia. "La búsqueda del pasado es un proceso cultural sin fin, permeado por los conflictos políticos relacionados con la acción social"127, sostiene Joanna Burke. Keith Jenkins argumenta que "[...] a principios del siglo XXI, podemos asumir que la historia está constituida como una compleja serie de narrativas - representaciones- del pasado [...] siempre hay multitud de visiones, no una visión, de lo que la historia es o pueda llegar a ser"128. En este sentido debemos, en mi opinión, apostar por una historia que permita lecturas sugerentes y efectivas, siendo consciente de los límites de tal lectura del pasado.

Quinto, una Historia que vaya más allá del materialismo histórico, si es que esto designa algo más o menos único, y que tenga en cuenta el poder de las ideas. Dicho de otra manera, para mí las ideas, lo ideacional, fruto y moldeador de lo material, es más relevante que lo puramente material. El carro de combate es muy importante, pero no anda solo, ni tiene dirección por sí mismo. Hay un conductor y un tirador que piensa, conduce y/o dispara por sus ideas, incluso, si son puros mercenarios.

Esta importancia de las ideas pude remitirnos a Collingwood ${ }^{129}$, para quien la Historia es una historia de las ideas. Puede entenderse en términos de las mentalidades de la Escuela de los Anales, de imaginarios sociales, ideologías, etc. Estamos hablando, por tanto, de una historia hermenéutica, que busque ponerse en la piel, en las cabezas, de los colectivos humanos en acción.

\footnotetext{
$125 \quad$ Ibídem, p. 184

126 Ibíd., pp. 184-185

127 BOURKE, Joanna, "Foreword" en JENKINS, Keith, MORGAN, Sue y MUNSLOW, Alan (eds.), Manifestos for History, Routledge, Londres, 2007, p. xxii.

128 JENKINS, Keith, MORGAN, Sue y MUNSLOW, Alan, "Introduction. On Fidelity and Diversity" en JENKINS, Keith, Repensar la Historia, Siglo XXI, Madrid, 2009, p. 1.

129 COLLINGWOOD, Robin G., The Idea of History, Oxford University Press, Oxford, 1994.
} 


\section{Excurso. Marx y no marxismo}

¿Por qué en un texto sobre historia y relaciones internacionales el marxismo aparece solo de vez en cuando?

La primera razón es lo engañoso del término marxismo. Marx fue un hombre del XIX que dejó un legado impresiónate, cargado de poder explicativo y lleno de pasión. Esta obra fue dilatada en el tiempo, estuvo sujeta a cientos de influencias y aparece, ocasionalmente, como contradictoria. A nadie puede exigirse una coherencia en las tesis que ha ido desgranando durante 40 años. Muerto Marx y con la bien intencionada ayuda de Engels, el Partido Socialdemócrata alemán inventó el marxismo. Esencia de catecismo, recetas y frases apropiadas para cada ocasión.

La obra iniciada por los socialdemócratas alemanes fue culminada, llegando a cotas burocráticas y simplificadoras pasmosas, iacordaros del Politzer!, por los soviéticos. Y oscureciendo su mensaje y espíritu gracias al rígido estructuralismo de Althusser y compañía.

Cuando este acuso al historiador británico Thompson de empirismo, este le devolvió la crítica con un golpe demoledor - Miseria de la teoría ${ }^{130}$-, una llamada a la realidad y al uso de la teoría para comprender, no para hacer exégesis teóricas.

Marx renacerá cuando el marxismo, tal y como lo hemos heredado de la II y III Internacional, se haya extinguido.

Sexto, Leopold Ranke expuso los fundamentos filosóficos del historicismo: "[...] los hechos y situaciones pasados son únicos e irrepetibles, y no pueden comprenderse en función de categorías universales, sino en virtud de los contextos propios y particulares"131. Esta es una concepción que define la historicidad radical de todos los fenómenos humanos, una concepción de la razón humana como histórica en contraste con la razón atemporal de los ilustrados ${ }^{132}$.

La primera consecuencia sería la primacía en el relato histórico de lo político. Los historicistas intentan crear unas "ciencias" sociales distintas a las ciencias naturales, en las que se originó el positivismo. Lo que varía en los historicistas son sus unidades de estudio, sus agentes, sus protagonistas. La cultura para Spengler, las civilizaciones para Toynbee, la dimensión sociológica del hombre para Weber, la capacidad imaginativa del ser humano para Colllingwood ${ }^{133}$.

La compresión prima sobre la explicación, la narración sobre la estructura, y la

\footnotetext{
130 THOMPSON, Edward P., Miseria de la teoría, Crítica, Barcelona, 1979.

131 Citado por AURELL, Jaume et. al., Comprender..., op. cit., p. 223.

132 Ibídem.

133 Ibíd., p. 239.
} 
hermenéutica sobre el análisis causal en el acceso al conocimiento del pasado ${ }^{134}$. Weber, por su parte, "sentó las bases epistemológicas para una nueva historia, al reconocer que todas las ciencias incluida la Historia, eran sistemas de conceptos más que una descripción de la realidad"135.

Séptimo, conviene tener en cuenta que hay muchos niveles estructurales y temporalidades, que no necesariamente funciona al unísono. Los diferentes niveles estructurales cambian y continúan a ritmo diferente. Las instituciones como estructuras durables, como permanencia, como red establecida y reglamentada de relaciones, pueden subsistir más allá de la función para las que, en su origen, fueron creadas. Esta "estructura de temporalidad" podríamos calificarla como inercia.

Pero hay otras "estructuras temporales" que permanecen, aun cuando la sociedad que las vio nacer y necesitó de ellas, haya quedado en el pasado. Una sociedad puede haber sufrido enormes cambios sociológicos, técnicos, culturales, etc., pero determinada o determinadas memorias permanecen sobrevolando e influyendo en el comportamiento humano. En este sentido, se producen baches generacionales dignos de estudio ${ }^{136}$. El análisis de un evento, coyuntura o proceso internacional, también es un relato. $Y$ no nos movemos tampoco en Relaciones Internacionales con los "hechos" crudos de la realidad, sino con la selección de elementos que, según nuestra teoría, nos parezcan pertinentes. Se da significado considerando, otra vez, nuestros presupuestos teóricos ("tales hechos tienen").

\section{Excurso. Carr y el rechazo del empirismo}

Carr definía y rechazaba el empirismo en la historia como la "convicción" de que todos los problemas pueden ser resueltos mediante la aplicación de algún principio no valorativo, como, por ejemplo, el que existe una solución objetivamente correcta y un camino para alcanzarla - los supuestos presupuestos de la ciencia transferidos a las ciencias sociales- ${ }^{137}$.

Carr atribuía la "debilidad y la falta de profundidad en tantos escritos políticos e históricos ingleses recientes" [...] [a la brecha] que "separa tan fatalmente a Marx de los pensadores de habla inglesa" [...] Marx no era un empirista. Estudiar la parte sin referencia al todo, el hecho sin referencia a su significación, el suceso sin referencia a su causa o consecuencia, la crisis particular sin referencia a la situación general, hubiera parecido a Marx un ejercicio estéril [en una época] en que vamos de crisis en crisis, en ausencia de toda línea rectora, el empirismo no basta"138.

\footnotetext{
134 AURELL, Jaume et. al., Comprender..., op. cit., pp. 306-307.

135 IGGERS, G. C., citado en ibíd., p. 247.

136 MANNHEIM, Karl, "El problema de las generaciones", REIS - Revista Española de Investigaciones Sociológicas, vol. 62, 1993, pp. 193-242.

137 DAVIES, Richard, "Nota introductoria (a la segunda edición)", Carr, Edward Hallett, op. cit. [edición de 2010], p. 53.

$138 \quad$ Ibídem, p. 56.
} 


\subsection{Una teoría de las Relaciones Internacionales para esta concepción de la historia}

Y si el "presente es historia", nuestra labor como internacionalistas difiere poco del trabajo de los historiadores. Así, la teoría de las Relaciones Internacionales -inevitablemente- se refiere de manera explícita a una filosofía de la historia. Que no sea explícita no significa que no exista, sino que se da por supuesta. Y puesto que la teoría de las Relaciones Internacionales puede ser considerada otra forma de historia, nuestra disciplina debe atender los cambios en las ideas e identidades que dan en la interacción en el tiempo ${ }^{139}$; así como enfatizar el papel de la Historia en el análisis de las relaciones internacionales.

El constructivismo se basa, meramente, en que las identidades e intereses de los actores cambian con la interacción, y, según nuestro parecer, a lo largo de un tiempo, en una duración larga, media y eventual. El mismo constructivismo necesita de la Historia, ya que la interacción y el cambio son ya Historia. Además, la interacción debe darse en un proceso más o menos largo para que merezca la pena tenerla en cuenta. El constructivismo, en su versión presentista, no es nada. El constructivismo necesita de la historia, o el constructivismo escribe Historia.

Para mí muy discutible opinión, la teoría de las Relaciones Internacionales debe ser esencialmente estatocéntrica, es decir, en relaciones internacionales los principales y más relevantes protagonistas son, en la mayoría de los casos, los estados en un sistema internacional desigual y jerárquico en poder y riqueza. Entiendo los estados, siguiendo a Fred Halliday ${ }^{140}$, como conjuntos, como formaciones sociales discretas (fronteras), que actúan en el sistema internacional, en principio, con una sola voz. Estos conjuntos son entramados de relaciones sociales políticas, económicas, culturales, identitarias, etc., con contradicciones y consensos que cambian y tienen continuidades en el tiempo (historia).

Se requiere una teoría de las Relaciones Internacionales histórica que narre, analice y de cuenta del devenir conflictivo de la humanidad, de la violencia, el poder y la riqueza como factores y motores persistentes en la historia, en nuestro pasado. Parafraseando a Marx, reconocer el papel de la violencia "como partera de la historia"141. Reconocer su papel en la creación del estado moderno, de la sociedad internacional (léase europea), y de su expansión con la descolonización ${ }^{142}$. Debe distinguirse "violencia" como uso de la fuerza en la coerción, de "formas de dominación", que -en algunos casos- se califican de violencia, como, por ejemplo, la violencia estructural de Galtung.

\footnotetext{
139 Este es el núcleo de lo que se ha venido a llamar en la las Relaciones Internacionales constructivismo. Su origen, hasta donde llega mi saber, está en BERGER, Peter y LUCKMANN, Thomas, La construcción social de la realidad, Amorrortu Editores, Buenos Aires, 1991, 10a edición.

140 HALLIDAY, Fred, Las relaciones internacionales en un mundo en transformación, Ediciones La Catarata, Madrid, 2002 [capítulo "El estado y la sociedad en las relaciones internacionales"].

141 Es una vulgarización de la frase de Marx en el capítulo 24 de El Capital, dedicado, como se sabe, a la acumulación originaria, Marx exclama: «La violencia [Gewalt] es la comadrona [Geburtshelfer] de toda sociedad vieja, que lleva en sus entrañas otra nueva. Es, por sí misma, una potencia [Potenz] económica»

142 La sociología histórica lo ha demostrado sin lugar a dudas. Pero también todos los historiadores. Para un ejemplo sociología histórica ver TILLY, Charles, "War making and State Making as Organized Crime" en EVANS, Peter, RUESDESCHEMEYER, Dietrich y SKOCPOL, Theda (eds.), Bringing the State... op. cit., y sobre la expansión de la sociedad internacional BULL, Hedley y WATSON, Adam (eds.), The expansión of International Society, Claredon Press, Oxford, 1989.
} 
Una narrativa que sea consciente de que las "soluciones" a los problemas de hoy, a sus conflictos, llevan en sí las semillas de los conflictos de mañana (El mito de Sísifo). Así, por ejemplo, la solución de dotar de una patria territorial a los judíos masacrados en Europa durante el régimen nazi, ha llevado al genocidio palestino de hoy ${ }^{143}$. Esta conclusión que recito a menudo, y que casi todo el mundo tacha de pesimista, puede serlo o no, más bien los adjetivos pesimista $u$ optimista tienen poco sentido en política y menos en relaciones internacionales.

\section{$Y$ final}

El pasado es un texto esquivo, incompleto, muchas veces parcialmente oculto, y de difícil compresión más allá de los hechos empíricos a los que puede tenerse un amplio acceso. Los historiadores leen ese pasado. En este caso, "leer" es una palabra literal porque el pasado está en las estanterías de las bibliotecas, en los documentos de los archivos accesibles, en objetos, ruinas, leyendas, memorias orales, etc., que los historiadores deben revisar, acoplar, y -con suerte- intentar encontrar un significado al conjunto. Y por parte de los internacionalistas, ser conscientes de que las "fotos fijas" no dicen mucho, la clave está en la sucesión de fotogramas.

\section{Bibliografía}

ALCOBERRO, Ramon, La filosofía de la historia: ¿un anacronismo?, Filosofía y pensamiento, http:// www.alcoberro.info/pdf/FiloHISTO01.pdf [Consultado el 25 de octubre de 2017].

AMIN, Samir, La desconexión, IEPALA, Madrid, 1988.

ANDERSON, Perry, Lineages of Absolutist State, Verso, Londres, 1985.

ARON, Raymond, Paz y guerra entre las naciones, Alianza Editorial, Madrid, 1985.

AURELL, Jaume, BALMACEDA, Catalina, BURKE, Peter y SOZA, Felipe, Comprender el pasado. Una historia de la escritura y el pensamiento histórico, Akal, Madrid, 2013.

BERGER, Peter y LUCKMANN, Thomas, La construcción social de la realidad, Amorrortu Editores, Buenos Aires, 1991.

BOURKE, Joanna, "Foreword" en JENKINS, Keith, MORGAN, Sue y MUNSLOW, Alan (eds.), Manifestos for History, Routledge, Londres, 2007, pp. xi-xii.

BRAUDEL, Fernand, Una lección de Historia, F.C.E, México D.C., 1989.

BUKOVANSKY, Mlada, Legitimacy and Power Politics, Princeton University Press, Princeton, 2002.

BULL, Hedley y Watson, Adam (eds.), The expansión of International Society, Claredon Press, Oxford, 1989.

BURBANK, Jane y COOPER, Frederick, Empires in World History. Power and the Politics of Difference, Princeton University Pres, Princeton, 2010.

BUTTERFIELD, Herbert, The Whig Interpretation of History, G. Bell and Sons, Londres, 1951 [1a edición en inglés de 1931].

CARR, Edward Hallett, International Relations between de two world wars. 1919-1939, Macmillan, Londres, 1990 [ 10 edición en inglés de 1939].

CARR, Edward Hallett, ¿Qué es la historia?, Ariel, Barcelona, 2010 [10 edición en inglés de 1961].

CARR, Edward Hallett, La crisis de los veinte años (1919-1939). Una Introducción al estudio de las Relaciones Internacionales, La Catarata, Madrid, 2004 [1 a edición en inglés de 1945].

COLLINGWOOD, Robin G., The Idea of History, Oxford University Press, Oxford, 1994.

DALE, Roger, "Nation state and international system The World System perspective" en McLENNAN, Gregor, HELD, David y HALL, Stuart, The Idea of the Modern State, Open University Press, Milton Keynes, 1984, pp. 183-207.

DAVIES, Richard, "Nota introductoria (a la segunda edición)" en CARR, Edward Hallett, ¿Qué es la historia?, Barcelona, Ariel, 2010 [1 $1^{\text {a }}$ edición en inglés de 1961].

\footnotetext{
143 Soy consciente de que el proyecto de construir una patria justa en Palestina es anterior al holocausto y fruto del movimiento sionista del finales del siglo XIX, pero el argumento de proporcionar una patria a "los que sobrevivieron a los campos de exterminio", fue ampliamente utilizado en 1948 en el reconocimiento internacional del estado de Israel.
} 
DEAN, Mitchell, Critical and effective histories, Routledge, Londres, 1994.

DUJOVNE, León, La filosofía de la historia. De Nietzsche a Toynbee, Galatea/Nueva Visión, Buenos Aires, 1957.

EVANS, Peter, RUESDESCHEMEYER, Dietrich y SKOCPOL, Theda (eds.), Bringing the State back in, Cambridge University Press, Cambridge, 1985.

FIELDHOUSE, David K., "Imperialism: an historical review", The Economic History Review, vol. 14, $\mathrm{n}^{\circ}$ 2, 1966, pp. 187-209.

FUKUYAMA, Francis, "The End of History?", The National Interest, no 16, 1989, pp. 3-18.

FUKUYAMA, Francis, The End of History and the Last Man, Free Press, Nueva York, 1992.

FOUCAULT, Michel, Nietzsche, la genealogía y la historia, Pre-Textos, Valencia, 1992.

FOUCAULT, Michel, Defender la sociedad. Curso del Collègue de France, 1975-1976, F. C. E., México D.C., 2000.

GADDIS, John L., The Long Peace. Inquiries into the History of the Cold War, Oxford University Press, Nueva York, 1987.

GADDIS, John Lewis, The United States and the end of the Cold War, Oxford University Press, Nueva York, 1992.

GADDIS, John L., We Now Know. Rethinking Cold War History, Clarendon Press, Oxford, 1997.

GILPIN, Robert, War and Change in World Politics, Cambridge University Press, Cambridge, 1981.

GUNDER FRANK, Andrè, The sociology of development and the underdevelopment of sociology, Pluto Press, Londres, 1971.

HALL, John A. (ed.), States in History, Basil Blackwell, Oxford, 1986.

HALLIDAY, Fred, Las relaciones internacionales en un mundo en transformación, Ediciones La Catarata, Madrid, 2002.

HOBSON, John A., The State and International Relations, Cambridge University Press, Cambridge, 2000.

HOBSON, John. M., Historical Sociology and International Relations, Cambridge, University Press, Cambridge, 2002.

HOBSON, John M. y LAWSON, George, "What is History in International Relations?", Millennium - Journal of international studies, vol. 37, no 2, 2008, pp. 415-435.

HUNTINGTON, Samuel P., "The Clash of Civilizations", Foreign Affairs, vol. 72, no 3, 1993, pp. 22-49.

HUNTINGTON, Samuel P., The Clash of Civilizations and the Remaking of World Order, Simon and Schuster Inc., Nueva York, 1996.

JENKINS, Keith, Repensar la Historia, Siglo XXI, Madrid, 2009.

JENKINS, Keith, MORGAN, Sue y MUNSLOW, Alan. (eds.), Manifestos for History, Routledge Londres, 2007.

JENKINS, Keith, MORGAN, Sue y MUNSLOW, Alan, "Introduction. On Fidelity and Diversity" en JENKINS, Keith, Repensar la Historia, Siglo XXI, Madrid, 2009.

KENNEDY, Paul, The Rise and Fall of the Great Powers: Economic Change and Military Conflict from 1500 to 2000, Lexington Books, Lexington, 1987.

KEPEL, Gilles, El terror entre nosotros. Una historia de la yihad en Francia, Península, Barcelona, 2016. KISSINGER, Henry, A World Restored, Grosset \& Dunlap, Nueva York, 1964.

KOSELLECK, Reinhart, Los estratos del tiempo: estudios sobre la historia, Paidós, Barcelona, 2001.

MANNHEIM, Karl, "El problema de las generaciones", REIS - Revista Española de Investigaciones Sociológicas, vol. 62, 1993, pp. 193-242.

MANN, Michael, The Sources of Social Power. Vol. I, A History of Power from the beginning to A.D. 1760, Cambridge University Press, Cambridge, 1986.

MANN, Michael, The Sources of Social Power. Vol. II, The Rise of Classes and Nation-States, 1760-1914, Cambridge University Press, Cambridge, 2012.

MANN, Michael, The Sources of Social Power. Vol. III, Global Empires and Revolutions, 1890-1945, Cambridge University Press, Cambridge, 1993.

MANN, Michael, The Sources of Social Power. Vol. IV, Globalizations, 1945-2011, Cambridge University Press, Cambridge, 2012.

MCNEILL, William H., The Rise of the West: A History of the Human Community, University of Chicago Press, Chicago, 1963.

MCNEILL, William H., A World History, Nueva York, Oxford University Press, Oxford, 1978.

NAVARRO PÉREZ, José, "Jacob Burckhardt, el escepticismo histórico y el pesimismo político", Respublica, $n^{\circ}$ 6, 2000, pp. 111-145.

PEÑAS, Francisco Javier, Occidentalización, fin de la Guerra Fría y relaciones internacionales, Alianza Editorial, Madrid, 1997.

PHILPOTT, Daniel, Revolutions in Sovereignty, Princeton University Press, Princeton, 2001.

RAE, Heather, State identities and the homogenisation of peoples, Cambridge University Press, Cambridge, 2002.

RENOUVIN, Pierre, "Introducción general" en RENOUVIN, Pierre (dir.), Historia de las relaciones internacionales, vol. I, Aguilar, Madrid, 1960. 
RENOUVIN, Pierre y DUROSELLE, Jean-Batiste, Introducción a la política internacional, Rialp, Madrid, 1968.

REUS-SMIT, Christian, The Moral Purpose of the State. Culture, Social Identity and Instutional Rationality, Princeton University Press, Princeton, 1999.

REUS-SMIT, Christian "Reading History through constructivist eyes", Millenium. Journal of International Studies, vol. 37, $\mathrm{n}^{\circ} 395,2008$, pp. 395-414.

ROBINSON, Ronald y GALLAGHER, John, Africa and the Victorians. The Official Mind of Imperialism, Macmillan, Londres, 1981.

ROTH, Philip, The dying animal, Houghton Mifflin Harcourt, Nueva York, 2001.

SCHROEDER, Paul W., The Transformation of European Politics 1763-1848, Oxford University Press, Oxford, 1996.

SCHOROEDER, Paul, "History and International Relations Theory: Not Use or Abuse, but Fit or Misfit", International Security, vol. 22, $\mathrm{n}^{\circ} 1,1997, \mathrm{pp} .64-74$.

SCHROEDER, Paul, "Why realism doesn't work well for International History? (Whether or not it represents a degenerate IR research strategy)" en VASQUEZ, John A. y ELMAN, Colin (eds.), Realism and balancing of Power: A New Debate, Prentice Hall, New Jersey, 2003.

SMITH, Anthony D., National Identity, Londres, Penguin Books, 1991.

THOMPSON, Edward P., "Prefacio" a La formación de la clase obrera en Inglaterra, 1780-1832, Barcelona, Laia, 1977, pp. XIII-XVIII.

THOMPSON, Edward P., Miseria de la teoría, Crítica, Barcelona, 1979.

TILLY, Charles (ed.), The formation of national states in Western Europe, Princeton, Princeton University Press, 1975.

TILLY, Charles, "War making and State Making as Organized Crime" en EVANS, Peter, RUESDESCHEMEYER, Dietrich y SKOCPOL, Theda (eds.), Bringing the State back in, Cambridge University Press, Cambridge, 1985, pp.169-188.

TILLY, Charles, Grandes estructuras, procesos amplios, comparaciones enormes, Alianza Editorial, Madrid, 1991.

TOYNBEE, Arnold J., Un estudio de la historia, Alianza Editorial, Madrid, 1970, [1ª edición en inglés de 1946].

WALLERSTEIN, Immanuel, El moderno sistema mundial vol. 1. La agricultura capitalista y los orígenes de la economía-mundo europea en el siglo XVI, Siglo XXI, Madrid, 1979.

WALLERSTEIN, Immanuel, El moderno sistema mundial, vol. II. El mercantilismo y la consolidación de la economía mundo europea, 1600-1750, Siglo XXI, Madrid, 1984.

WALLERSTEIN, Immanuel, "Análisis de los sistemas mundiales" en GIDDENS, Anthony y TURNER, Jonathan (eds.), La teoría social hoy, Alianza Editorial, Madrid, 1990, pp. 398-417.

WALLERSTEIN, Immanuel, El capitalismo histórico, Siglo XXI, Madrid, 1998.

WALTZ, Kenneth, A Theory of International Relations, McGraw-Hill, Nueva York, 1979.

WENDT, Alexander, Social Theory of International Politics, Cambridge University Press, Cambridge, 1999.

WIGHT, Martin, Systems of States, Leicester University Press, Bristol, 1977.

WIGHT, Martin, Power Politics, Leicester University Press, Bristol, 1978.

WIGHT, Martin International Relations. The Three Traditions, Leicester University Press, Bristol, 1991.

WIGHT, Martin, "Why is there no International Theory" en WIGHT, Martin y BUTTERFIELD, Herbert (eds. ), Diplomatic Investigations: Essays in the Theory of International Politics, Allen and Unwin, Londres, 1966, pp. 35-48.

WOLF, Eric, Europe and the Peoples without History", California University Press, Berklye, 1982.

WRIGHT, Donald, "SEWELL, Keith C., Herbert Butterfield and the Interpretation of History (Studies in Modern History). New York: Palgrave Macmillan. 2005. Pp. xii, 280" en The American Historical Review, vol. 111, n², 2006.

ZORGBIBE, Charles, Historia de las relaciones internacionales vol. I. De la Europa de Bismarck hasta el final de la Segunda Guerra Mundial, Alianza Editorial, Madrid, 1997.

ZORGBIBE, Charles, Historia de las relaciones internacionales vol. II. Del sistema de Yalta a nuestros días, Alianza Editorial, Madrid, 1997. 


\section{RELACIONES INTERNACIONALES}

Revista académica cuatrimestral de publicación electrónica Grupo de Estudios de Relaciones Internacionales (GERI) Universidad Autónoma de Madrid, España

www.relacionesinternacionales.info

ISSN 1699 - 3950

ff facebook.com/RelacionesInternacionales

twitter.com/RRInternacional 